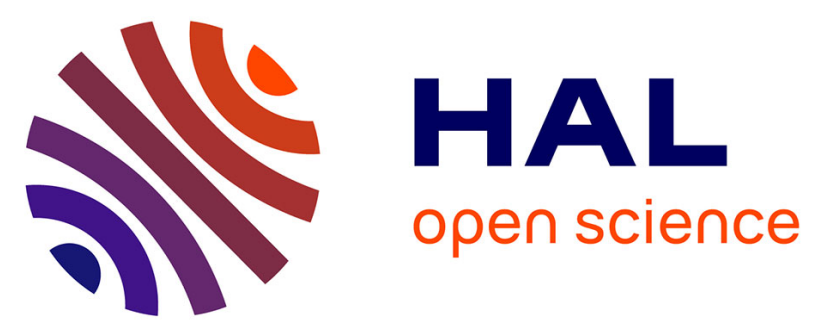

\title{
Aronia - citrus juice (polyphenol-rich juice) intake and elite triathlon training: a lipidomic approach using representative oxylipins in urine
}

\author{
Libia Alejandra García-Flores, Sonia Medina, Cristina Gomez, Craig
}

Wheelock, Roberto Cejuela, José Miguel Martínez-Sanz, Camille Oger,

Jean-Marie Galano, Thierry Durand, Álvaro Hernández-Sáez, et al.

\section{To cite this version:}

Libia Alejandra García-Flores, Sonia Medina, Cristina Gomez, Craig Wheelock, Roberto Cejuela, et al.. Aronia - citrus juice (polyphenol-rich juice) intake and elite triathlon training: a lipidomic approach using representative oxylipins in urine. Food and Function, 2018, 9 (1), pp.463-475. 10.1039/C7FO01409K . hal-02612564

\section{HAL Id: hal-02612564 \\ https://hal.science/hal-02612564}

Submitted on 3 Jun 2021

HAL is a multi-disciplinary open access archive for the deposit and dissemination of scientific research documents, whether they are published or not. The documents may come from teaching and research institutions in France or abroad, or from public or private research centers.
L'archive ouverte pluridisciplinaire HAL, est destinée au dépôt et à la diffusion de documents scientifiques de niveau recherche, publiés ou non, émanant des établissements d'enseignement et de recherche français ou étrangers, des laboratoires publics ou privés. 


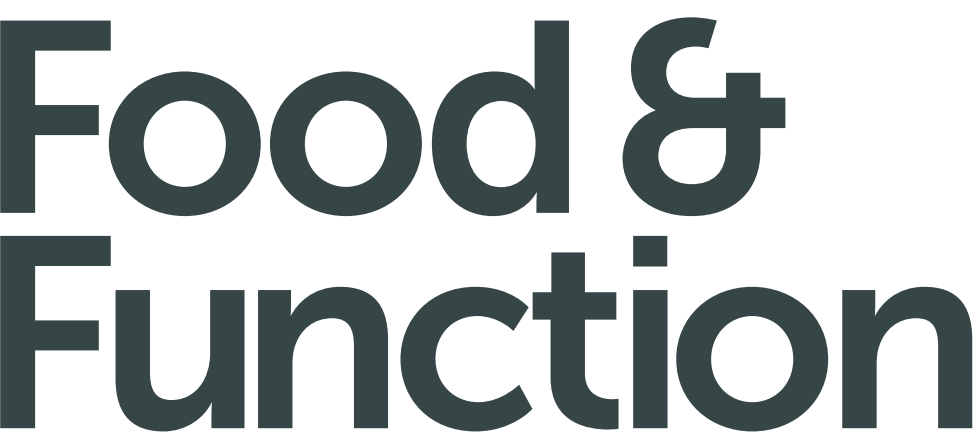

\section{Accepted Manuscript}

This article can be cited before page numbers have been issued, to do this please use: L. A. Garcia-

Flores, S. Medina, C. Gómez, C. Wheelock, R. Cejuela-Anta, J. M. Martínez-Sanz, C. Oger, J. Galano, T. Durand, Á. Hernández Sáez, F. Ferreres and A. Gil-Izquierdo, Food Funct., 2017, DOI:

\section{Food \& Function}

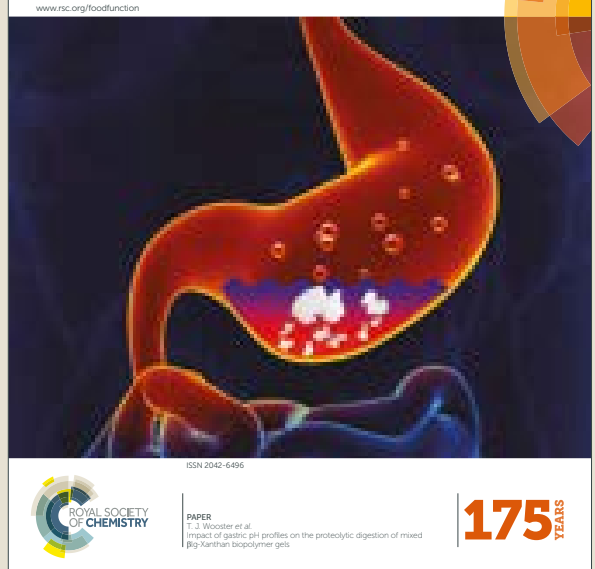

This is an Accepted Manuscript, which has been through the Royal Society of Chemistry peer review process and has been accepted for publication.

Accepted Manuscripts are published online shortly after acceptance, before technical editing, formatting and proof reading. Using this free service, authors can make their results available to the community, in citable form, before we publish the edited article. We will replace this Accepted Manuscript with the edited and formatted Advance Article as soon as it is available.

You can find more information about Accepted Manuscripts in the author guidelines.

Please note that technical editing may introduce minor changes to the text and/or graphics, which may alter content. The journal's standard Terms \& Conditions and the ethical guidelines, outlined in our author and reviewer resource centre, still apply. In no event shall the Royal Society of Chemistry be held responsible for any errors or omissions in this Accepted Manuscript or any consequences arising from the use of any information it contains. 
1 Aronia-citrus juice intake (polyphenol rich juice) and elite triathlon training: A lipidomic 2 approach using representative oxylipins in urine

Libia Alejandra García-Flores ${ }^{1, \ddagger}$, Sonia Medina ${ }^{1,{ }^{*}}$, Cristina Gómez ${ }^{2}$, Craig E. Wheelock ${ }^{2}$, Roberto Cejuela ${ }^{3}$, José Miguel Martínez-Sanz ${ }^{3}$, Camille Oger ${ }^{4}$, Jean-Marie Galano ${ }^{4}$, Thierry Durand ${ }^{4}$, Álvaro Hernández-Sáez ${ }^{5}$, Federico Ferreres ${ }^{1}$, and Ángel Gil- Izquierdo ${ }^{1 *}$.

1 Department of Food Science and Technology. CEBAS-CSIC. Campus de Espinardo. P.O. Box 164, 30100 Espinardo, Murcia, Spain.

${ }^{2}$ Division of Physiological Chemistry II, Department of Medical Biochemistry and Biophysics, Stockholm; Karolinska Institutet, Stockholm

${ }^{3}$ Faculty of Education. University of Alicante. Campus de San Vicente del Raspeig, Alicante, Spain

4 Institut des Biomolécules Max Mousseron (IBMM), UMR 5247, University Montpellier I and II, ENSCM, Faculty of Pharmacy, Montpellier, France

${ }^{5}$ Faculty of Chemistry. University of Murcia. Campus Espinardo, 30100 Espinardo, Murcia, Spain

"These two authors have contributed equally to this work. "Corresponding authors:

Angel Gil-Izquierdo (accept correspondence and proofs)

And Sonia Medina Research Group on Quality, Safety, and Bioactivity of Plant Foods, Department of Food Science and Technology, CEBAS (CSIC), P.O. Box 164, 30100 Campus University Espinardo, Murcia, Spain Tel: +34 968396363; fax: +34 968396213 . 


\section{Abstract}

39

41 during 145 days of training. Within this time span, 45 days were dedicated to examining the effects

42 of the intake of a beverage rich in polyphenols (one serving: $200 \mathrm{~mL}$ per day) supplemented in their

43 diet. The beverage was a mixture of citrus juice (95\%) and Aronia melanocarpa juice (5\%) (ACJ).

44 Fifty-two oxylipins were analyzed in urine. The quantification was carried out using solid-phase

45 extraction,liquid chromatography coupled to triple quadrupole mass spectrometry . The physical

46 activity decreased the excretion of some PGs, IsoPs, TXs, LTs metabolites from arachidonic acid, $\gamma$ -

47 dihomo-linolenic acid, and eicosapentaenoic acid. The ACJ also reduced the excretion of 2,3-dinor-

$48 \quad 11 \beta-\mathrm{PGF}_{2 \alpha}$ and $11-\mathrm{dh}-\mathrm{TXB}_{2}$, although the levels of other metabolites increased after juice 49 supplementation ( $\mathrm{PGE}_{2}$, 15-keto-15- $\mathrm{F}_{2 \mathrm{t}}-\mathrm{IsoP}, \quad 20-\mathrm{OH}-\mathrm{PGE}_{2}, \quad \mathrm{LTE}_{4}$, and 15-epi-15- $\left.\mathrm{E}_{2 \mathrm{t}}-\mathrm{IsoP}\right)$, 50 compared to the placebo. The metabolites that increased in abundance have been related to vascular 
64

65

66

67

68

69

70

71

72

73

74

75

76

77

78

79

80

81

82

83

84

85

86

87

88

89

\section{Introduction}

Currently, it is not clear whether polyphenol supplementation exerts beneficial effects on oxidative stress (OS) and/or the inflammation status in the area of sport. ${ }^{1,2}$ Many studies analyzing the effects of dietary polyphenols on human health have been performed in the last decade, with increasing numbers of reports studying flavonoids and polyphenols in general. ${ }^{3,4}$ Polyphenol supplementation in exercise studies includes mainly extracts, juices, infusions, or increased intake of polyphenol-rich foods (including functional foods). ${ }^{1}$ In athletes of different disciplines, polyphenols have shown an antioxidant potential that can be beneficial for the reduction of the effects of oxidative damage during intense exercise, apparently without an anti-inflammatory effect. ${ }^{4}$ Furthermore, it is also necessary to take into account the effect of the physical exercise, since this external factor has shown a positive effect on lipid peroxidation and/or OS as a consequence of its chronic practice. ${ }^{5-8}$ In 2005, Petersen ${ }^{9}$ mentioned that regular exercise induces an anti-inflammatory response rather than a pro-inflammatory response. Regular exercise training promotes increases in enzymatic and non-enzymatic antioxidants in muscle fibers, resulting in improved endogenous protection against exercise-mediated oxidative damage. ${ }^{10}$

In the field of sports science and elite sports environment, biomarkers are used to make inferences about the athlete's underlying physiology and health, particularly in the context of adaptation to training and the impact of environmental stressors. ${ }^{11}$ Metabolomics and lipidomics data indicate that intensive and prolonged exercise is associated with extensive lipid mobilization and oxidation, including many components in the pathway of linoleic acid conversion and related oxidized derivatives or oxylipins. ${ }^{12}$ The lipid metabolism constitutes a network of pathways that are related at multiple biosynthetic hubs. ${ }^{13}$ Oxygenated lipids are known collectively as oxylipins. ${ }^{14}$ Eicosanoids, a subset of oxylipins, are signaling molecules that have been used as biomarkers for a global picture of changes in lipid peroxidation and vascular events as a consequence of chronic exercise and the supplementation of polyphenols. ${ }^{5-8,12-14}$ Eicosanoids are a family that includes prostaglandins (PGs), leukotrienes (LTs), thromboxanes (TXs), and isoprostane (IsoPs), which are 
lipid mediators involved in the physiopathology of all organs, tissues, and cells. ${ }^{17}$ The PGs and

91 TXs, collectively termed prostanoids, are formed when arachidonic acid (AA), a 20-carbon

92 unsaturated fatty acid, is released from the plasma membrane by phospholipases and metabolized

93 by the sequential actions of prostaglandin $\mathrm{G} / \mathrm{H}$ synthase, or cyclooxygenase (COX). $\mathrm{TXA}_{2}$ is

94 synthesized from prostaglandin $\mathrm{H}_{2}\left(\mathrm{PGH}_{2}\right)$ by thromboxane synthase, and it is non-enzymatically

95 degraded into biologically inactive thromboxane $\mathrm{B}_{2}\left(\mathrm{TXB}_{2}\right) .{ }^{18}$ On the other hand, there are four

96 primary bioactive $\mathrm{PGs}$ generated in vivo: prostaglandin $\mathrm{E}_{2} \quad\left(\mathrm{PGE}_{2}\right)$, prostacyclin $\left(\mathrm{PGI}_{2}\right)$,

97 prostaglandin $\mathrm{D}_{2}\left(\mathrm{PGD}_{2}\right)$, and prostaglandin $\mathrm{F}_{2 \alpha}\left(\mathrm{PGF}_{2 \alpha}\right) .{ }^{18}$ Besides $\mathrm{AA}$, another polyunsaturated

98 fatty acid (PUFA) is dihomo- $\gamma$-linolenic acid (DGLA), a 20-carbon n-6 (C20:3 n-6) derived in vivo

99 from $\alpha$-linolenic acid (c18:3 n-6). Through a series of free radical reactions, COX metabolizes

100 DGLA and AA to form various bioactive metabolites: namely, the 1 and the 2 series of PGs (PG1

101 and PG2), respectively. ${ }^{19}$ The LTs also contain 20 carbons, but lack the 5 -carbon ring structure. ${ }^{20}$

102 They are AA metabolites derived from the action of 5-LOX (5-lipoxygenase). The immediate

103 product of 5-LOX is $\mathrm{LTA}_{4}$ (leukotriene $\mathrm{A}_{4}$ ), which is enzymatically converted into either $\mathrm{LTB}_{4}$

104 (leukotriene B4), by $\mathrm{LTA}_{4}$ hydrolase, or $\mathrm{LTC}_{4}$ (leukotriene $\mathrm{C}_{4}$ ), by $\mathrm{LTC}_{4}$ synthase. ${ }^{20}$ The

105 glutathione conjugate forms are termed cys-LTs (cysteinyl leukotrienes) and include leukotriene $\mathrm{C}_{4}$

$106\left(\mathrm{LTC}_{4}\right)$, leukotriene $\mathrm{D}_{4}\left(\mathrm{LTD}_{4}\right)$, and leukotriene $\mathrm{E}_{4}\left(\mathrm{LTE}_{4}\right)$. The Cys-LTs are potent

107 bronchoconstrictors and vasoconstrictors. ${ }^{13}$ The biosynthesis of eoxins (EX), structural isomers of

108 cys-LTs, is initiated via the 15-lipoxygenase (15-LOX) pathway. Also, there is another pathway that

109 occurs in vivo through a free radical-mediated mechanism to yield a series of PG-like compounds

110 termed IsoPs, independent of the catalytic activity of COX. ${ }^{21,22}$ The $\mathrm{F}_{2}$-isoprostanes ( $\mathrm{F}_{2}$-IsoPs $)$ are

111 an in vivo index of OS. ${ }^{16}$ Further, $\mathrm{F}_{1}$-phytoprostanes $\left(\mathrm{F}_{1}\right.$-PhytoPs $)$ and $\mathrm{F}_{3}$-IsoPs are also generated

112 from $\alpha$-linolenic acid (ALA) and eicosapentaenoic acid (EPA). ${ }^{23,}{ }^{24}$ Finally, 3-series prostanoids,

113 derived from COX oxidation of EPA, may mediate the anti-inflammatory effects of this fatty acid. 
Based on the preceding, the primary goal of this randomized, double-blind, placebo

116

117

118

119

120

121

122

124

controlled, and crossover study was to ascertain the effects of a serving (200 mL) of Aronia-citrus Juice (ACJ) on the generation and metabolism of oxylipins, using a lipidomic approach. Also, the study design allowed the assessment of the changes produced by elite training sessions. We screened biomarkers from AA via LOX (LTs, cysLTs, and EXs), as well as other IsoPs, PGs, and TXs that complement our schematic of oxylipins (52 lipid mediators (Figure1)).

\section{Materials and methods}

\section{Physical characteristics of participants}

The anthropometric measurements were made according to the International Society of Advancement of Kinanthropometry (ISAK), ${ }^{26}$ and all tests were performed by the same, internationally certified anthropometrist (Level 2 ISAK) with the objective of decreasing technical errors of measurement. The body composition was determined by GREC Kinanthropometry consensus, ${ }^{27}$ using a model consisting of total fat by Withers' formula, ${ }^{28}$ lean weight by the procedure described by Leet et al., ${ }^{29}$ and residual mass by the difference in the weight (Table 1)

\section{Dietary intake}

The calculation of the dietary parameters and caloric intake was accurately designed and overviewed during the experimental intervention by nutritionists, using specific software for the calculation (website: http://www.easydiet.es and with the additional assistance of the Spanish and USDA databases (http://www.bedca.net/ and http://www.nal.usda.gov/fnic/foodcomp/search/). The dietary assessment and planning were based on the sport nutrition guidelines. ${ }^{30,31}$

\section{Aronia-citrus juice and Placebo beverage}

The polyphenol rich juice composition was based on a mixture of citrus juice (95\%) with added Aronia melanocarpa juice (5\%). This juice was developed on a industrial pilot scale (HERO Spain S.A., Alcantarilla, Murcia) with organoleptically-acceptable criteria to mimic the flavonoids 
composition of original beverage developed by Gonzales-Molina et al. ${ }^{32}$ The nutrients content and caloric supply of the ACJ that the triathletes consumed are summarized in Table 2, detailing the percentage contribution of the juice to the total diet.

The placebo beverage composition was based on a mixture of water, authorized red dye, flavoring, and sweetener, giving sensory characteristics close to those of ACJ (see Garcia-Flores et al., ${ }^{33,34}$ for further information about ACJ composition and nutritional planning).

\section{Training load}

The training load quantification was performed using the Objective Load Scale (ECOs) developed by Cejuela-Anta and Esteve-Lanao. ${ }^{35}$ The training loads designed by the triathletes in the present work were similar to those found in other studies. ${ }^{5,30,33}$ This method used in the current work allowed the quantification of the training loads in triathlon (swim, bike, run, and transitions).

${ }^{37}$ The values of daily and weekly training were determined and summarized to assess the ECOs of each volunteer, depending on their physical characteristics and the intensity of the training program (the ECOs data presented in this work are the average of the individual ECOs of the triathletes). The variations of the ECOs are displayed in Figure 2 for better orientation.

\section{Study design}

Sixteen triathletes (6 training women and 10 training men) from the University of Alicante (Spain) agreed to participate in the project. An elite athlete in the context of sports medicine is an athlete with potential for competing in the Olympics or as a professional athlete. ${ }^{38}$ The volunteers were non-smokers, had stable food habits, and did not receive any medication (the specific absence of acute administration of anti-inflammatory drugs) during the experimental procedure. The study was approved by the Bioethics Committee of the University Hospital of Murcia and was in accordance with the Declaration of Helsinki. All participants provided written informed consent to a protocol approved by the institution. ${ }^{39}$ The recruitment started on $28^{\text {th }}-29^{\text {th }}$ October 2010 and was 
163

164

165

166

167

168

169

170

171

172

173

174

175

176

completed on $24^{\text {th }}-25^{\text {th }}$ March 2011. This study was a randomized, double-blind, placebo controlled, and crossover design (Figure 2) and was previously approved by nutritional experts. We assumed an equal allocation of volunteers to each beverage using computer-generated simple randomization with consecutive codes linked to the preparation of the placebo or ACJ. An impartial outsider, without the knowledge of the study, helped us to select the randomization code and indicated the assignment order. The volunteers remained blinded throughout study as well as the researchers responsible for the outcome measurements and the data analysis (see Garcia-Flores et al., ${ }^{33,}{ }^{34}$ for further information).

\section{Urine sample collection and preparation}

Twenty-four-hour urine samples were collected at the end of each stage (C-B, control baseline, C-T, control training, placebo intake stage, ACJ: Aronia-citrus juice intake stage, and CP$\mathrm{T}$, control post-training). All samples collected were immediately frozen $\left(-80{ }^{\circ} \mathrm{C}\right)$ to preserve the sample integrity until the time of analysis.

\section{Chemicals and analytes}

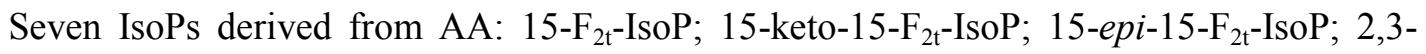

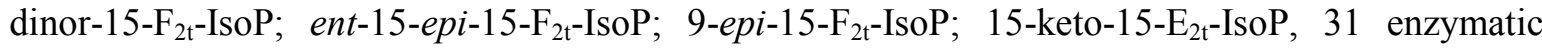
metabolites of $\mathrm{AA}: \mathrm{PGD}_{2}$; $\mathrm{PGDM}$ (PGD metabolite); tetranor-PGDM lactone (tetranor-PGD metabolite lactone); $11-\beta-\mathrm{PGF}_{2 \alpha} ; 2,3-$ dinor-11- $\beta-\mathrm{PGF}_{2 \alpha} ;$ tetranor-PGJM (tetranor-PGJ metabolite); tetranor-PGDM (tetranor-PGD metabolite); 6-keto-PGF $1 \alpha ; \mathrm{PGE}_{2} ; 20-\mathrm{OH}-\mathrm{PGE}_{2}$; tetranor-PGEM (tetranor-PGE metabolite); tetranor-PGAM (tetranor-PGA metabolite); 13,14-dihydro-15-keto$\mathrm{PGE}_{1} ; \quad$ 13,14-dihydro-15-keto-PGE $2 ; \quad$ 13,14-dihydro-15-keto-PGF $2 \alpha ; \quad \mathrm{PGF}_{2 \alpha}, \quad$ tetranor-PGFM (tetranor-PGF metabolite); 20-OH-PGF $2 \alpha ; 19(\mathrm{R})-\mathrm{OH}-\mathrm{PGF}_{2 \alpha} ;$ 15-keto-PGF ${ }_{2 \alpha}$, thromboxane $\mathrm{B}_{2}\left(\mathrm{TXB}_{2}\right) ;$ 2,3-dinor-TXB $\mathrm{TX}_{2}$;1-dehydro-thromboxane $\mathrm{B}_{2,}\left(11\right.$-dh- $\left.\mathrm{TXB}_{2}\right)$; leukotriene (LT) $\mathrm{B}_{4}, 20$ carboxy-LTB 4 , 20-hydroxy-LTB 4 , 6-trans- $\mathrm{LTB}_{4} ; \mathrm{LTC}_{4} ; \mathrm{LTE}_{4} ; \mathrm{EXC}_{4}$; and $\mathrm{EXE}_{4}$, four metabolites 
187

188

189

190

191

192

193

194

195

196

197

198

199

200

201

202

203

204

205

206

207

208

209

of DGLA ( $\left.\mathrm{PGE}_{1} ; \mathrm{PGF}_{1 \alpha} ; 15-\mathrm{F}_{1 \mathrm{t}}-\mathrm{IsoP} ; 15-\mathrm{E}_{1 \mathrm{t}}-\mathrm{IsoP}\right)$, and one metabolite of EPA (17-trans-PGF $\left.\mathrm{PG}_{3 \alpha}\right)$ were purchased from Cayman Chemicals (Ann Arbor, MI , USA). The authentic markers $\left[{ }^{2} \mathrm{H}_{4}\right]-$ 13,14-dihydro-15-keto-PGE $1, \quad\left[{ }^{2} \mathrm{H}_{4}\right]-13,14$-dihydro-15-keto- $\mathrm{PGE}_{2}, \quad\left[{ }^{2} \mathrm{H}_{4}\right]$-13,14-dihydro-15-keto$\mathrm{PGF}_{2 \alpha},\left[{ }^{2} \mathrm{H}_{4}\right]$-6-keto $\mathrm{PGF}_{1 \alpha},\left[{ }^{2} \mathrm{H}_{4}\right]-\mathrm{TXB}_{2}, \quad\left[{ }^{2} \mathrm{H}_{4}\right]-20$-carboxy-LTB ${ }_{4},\left[{ }^{2} \mathrm{H}_{4}\right]-\mathrm{LTB}_{4}$, and $\left[{ }^{2} \mathrm{H}_{4}\right]-8,12$-iso$\mathrm{iPF}_{2 \alpha}$-VI were also purchased from Cayman Chemicals.

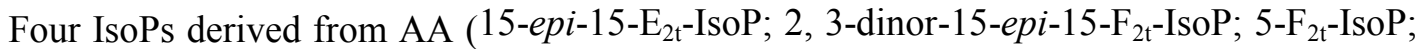
5-epi-5- $\left.\mathrm{F}_{2 \mathrm{t}}-\mathrm{IsoP}\right)$ and two metabolites of EPA (8- $\mathrm{F}_{3 \mathrm{t}}$-IsoPs and 8-epi-8- $\mathrm{F}_{3 \mathrm{t}}$-IsoPs) were synthesized according to our published procedures, ${ }^{40-44}$ while 2, 3-dinor-6-keto-PGF ${ }_{1 \alpha},\left[{ }^{2} \mathrm{H}_{3}\right]$-2, 3-dinor-6-keto$\mathrm{PGF}_{1 \alpha}, \mathrm{EXD}_{4}, 15-\mathrm{F}_{2 \mathrm{c}}$-IsoPs, and $\left[{ }^{2} \mathrm{H}_{4}\right]-15-\mathrm{F}_{2 \mathrm{c}}$-IsoPs were provided as described by Balgoma, et al., $2013^{45}$. The enzyme $\beta$-glucuronidase, type H2 from Helix pomatia, and BIS-TRIS (Bis-(2hydroxyethyl)-amino-tris(hydroxymethyl)-methane) were from Sigma-Aldrich (St. Louis, MO, USA). All LC-MS grade solvents were from J.T. Baker (Phillipsburg, NJ, USA). The Strata X-AW, $100 \mathrm{mg} 3 \mathrm{~mL}^{-1}$ SPE cartridges were purchased from Phenomenex (Torrance, CA, USA). Ammonium acetate, methoxyamine hydrochloride, and isopropanol were purchased from SigmaAldrich. Milli-Q ultrapure deionized water was used (Millipore Corporation, Billerica, MA). Methanol and acetonitrile were from Rathburn (Walkerburn, Scotland, UK). Acetone, acetic acid, and formic acid were from Fisher. Aqueous ammonia $(25 \%, w / v)$ was from Merck (Darmstadt, Germany).

\section{UHPLC-MS/MS analyses}

The samples were analyzed according to two methods described previously by Medina, et al. ${ }^{46}$ and Balgoma, et al. ${ }^{45}$, for the purpose of a deeper analysis of the generation and metabolism of oxylipins by our volunteers.

\section{UHPLC-QqQ-MS/MS for thirty-seven metabolites}


The separation of the metabolites present in the urine was performed using a UHPLC

211 coupled with a 6460 QqQ-MS/MS (Agilent Technologies, Waldbronn, Germany), using the set-up

212 described by Medina, et al. ${ }^{46}$. The main changes are as follows: after being clarified with

$213 \mathrm{MeOH} / \mathrm{HCl}(200 \mathrm{mM})$, the urine samples were centrifuged at $10000 \mathrm{rpm}$ for $5 \mathrm{~min}$. The solid phase

214 extraction was as follows: 1) preconditioning of cartridge with $\mathrm{MeOH}(2 \mathrm{~mL})$ and then MilliQ

215 water (2 mL); 2) loading of urine sample; 3) washing of cartridge with MilliQ water $(4 \mathrm{~mL}) ; 4)$

216 elution of cartridge with $\mathrm{MeOH}(1 \mathrm{~mL})$. Subsequently, the $\mathrm{MeOH}$ was evaporated from the extract

217 by speed Vac concentrator and the extract was reconstituted in $200 \mu \mathrm{L}$ of mobile phase (A:B)

218 (90:10). The changes in the identification and quantification of metabolites were as follows:

219 chromatographic separation was carried out on an ACQUITY UPLC BEH $\mathrm{C}_{18}$ column $(2.1 \times 150$

$220 \mathrm{~mm}, 1.7 \mu \mathrm{m}$; Waters), the column temperatures being $6{ }^{\circ} \mathrm{C}$ (left) and $6{ }^{\circ} \mathrm{C}$ (right). The flow rate was

$2210.15 \mathrm{~mL} \mathrm{~min}^{-1}$, using the linear gradient scheme (t, \%B): $(0.00 ; 60),(7.00 ; 60),(7.01 ; 73),(10.00$;

$22273),(10.01 ; 80),(18.00 ; 100),(19.00 ; 100)$, and $(19.01 ; 60)$. The operating conditions for the MS

223 parameters were as follows: gas flow: $8 \mathrm{~L} \mathrm{~min}^{-1}$, nebulizer: 30 psi, capillary voltage: $4000 \mathrm{~V}$, nozzle

224 voltage: $2750 \mathrm{~V}$, gas temperature: $325^{\circ} \mathrm{C}$, and jet stream gas flow: $8 \mathrm{~L} \mathrm{~min}^{-1}$. The MS parameters

225 were in the range of 50 to $160 \mathrm{~V}$ and the collision energy was in the range of 0 to $24 \mathrm{~V}$. The

226 acquisition time was $19.01 \mathrm{~min}$ for each sample, with a post-run of $3.0 \mathrm{~min}$ for the column

227 equilibration. The quantification of the oxylipins was carried out by daily preparation of calibration

228 curves (concentration range $3.9 \mathrm{nM}$ to $1 \mu \mathrm{M}$ ) using standard solutions. The matrix effect, recovery

229 of extraction, and overall process efficiency for each analyte were assessed using post-extraction

230 addition, established by Matuszewski, et al. ${ }^{47}$. The values were within the requested range for all 231 the metabolites.

The sensitivity, precision, and accuracy were established with the same parameters by the

233 Guidance for Industry-Bioanalytic Method Validation (the intraday and interday values were in the

234 range of $80-120 \%$ for all the metabolites). ${ }^{48}$ By this method, the metabolites determined were: 
PGDM, $\mathrm{PGD}_{2}$, tetranor-PGDM lactone, $11-\beta-\mathrm{PGF}_{2 \alpha}$, 2,3-dinor-11 $\beta-\mathrm{PGF}_{2 \alpha}$, tetranor-PGDM, tetranorPGJM, $\mathrm{PGE}_{2}, 20-\mathrm{OH}-\mathrm{PGE}_{2}$, tetranor-PGEM, tetranor-PGFM, 15-keto- PGF $_{2 \alpha}, 20-\mathrm{OH}-\mathrm{PGF}_{2 \alpha}, 19$ (R)-OH-PGF $F_{2 \alpha}$, 2,3-dinor-6-keto $\mathrm{PGF}_{1 \mathrm{a}}$, 6-keto $\mathrm{PGF}_{1 \mathrm{a}}, 15-\mathrm{F}_{2 \mathrm{t}}-\mathrm{IsoP}, 15-\mathrm{keto}-15-\mathrm{F}_{2 \mathrm{t}}-\mathrm{IsoP}$, 15-epi-

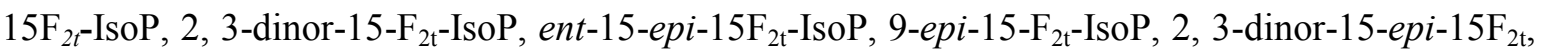

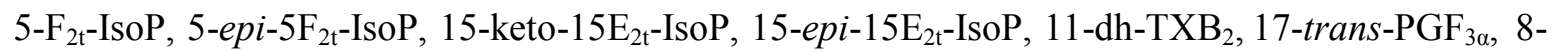

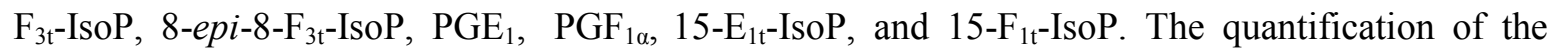
IsoPs, PGs, and TXs detected was performed using authentic markers. Data acquisition and processing were performed using Mass Hunter software version B.04.00 (Agilent Technologies).

\section{UHPLC-TQ-MS/MS for sixteen metabolites}

For the remaining 16 lipid metabolites (LTs, PGs, TXs, and IsoPs), two different analytical methods based on Balgoma et al. ${ }^{45}$, using the same analytical platform: UPLC Acquity- coupled to a Xevo TQS mass spectrometry system (Waters, Milford, MA) (LC-MS/MS).

\section{Statistical analysis}

The metabolites were analyzed individually as well as by series or family, using the excretion values $\left(\mu \mathrm{g} 24 \mathrm{~h}^{-1}\right)$ obtained throughout the study (C-B, C-T, placebo stage, ACJ stage, and CP-T). The 24-h urine was used for the absolute calculation of the amount of the LTs, EXs, IsoPs, PGs, and TXs excreted; the volume of urine excreted by the volunteers was $1212.42 \pm 716.50 \mathrm{~mL}$ $24 \mathrm{~h}^{-1}$, on average, over the assay. The data shown are the mean $\pm \mathrm{SD}$ (Table 3), as well as the quartiles (upper values 75\%, median 50\%, and lower values 25\%) (Figure 3). We employed nonparametric statistical tests since the data did not satisfy the assumption of normality. The Friedman test was used; if the $P$-value was significant, the post hoc Wilcoxon signed-rank test was used to decide which groups were significantly different from each other. The Bonferroni correction was applied, this correction was calculated by dividing the $P$-value $(P=0.05)$ by the number of tests, namely 10 (if the metabolite was detected in all the stages). Thus, our results were adjusted to 
$P \leq 0.005$. The statistical analyses were made using the SPSS 23.0 software package (LEAD

260

261

Technologies, Inc. Chicago, USA). The graphs were plotted using the Sigma Plot 12.0 software package (Systat Software, Inc., SigmaPlot for Windows).

\section{Results and Discussion}

Currently, the evidence is insufficient to make recommendations for the use of polyphenol supplementation by elite athletes. ${ }^{1,4,49,50}$ So, we wanted to make an in-depth examination of the primary lipid peroxidation biomarkers using a study design which allows observation of the effects of physical exercise and polyphenolic-rich beverage intake. A total of 52 oxylipins were screened in the triathletes' urine (Table 3). The mass spectral information of the oxylipins identified was based on Medina et al. ${ }^{46}$ and Balgoma et al. ${ }^{45}$ In total, 37 metabolites - 17 PGs, 14 IsoPs, two LTs, one EX, and three TXs - were detected in the urine samples of the triathletes. Therefore, 15 metabolites $\left(\mathrm{PGD}_{2}\right.$, tetranor-PGJM, 6-keto-PGF ${ }_{1 \alpha}, 20-\mathrm{OH}-\mathrm{PGF}_{2 \alpha}, 19(\mathrm{R})-\mathrm{OH}-\mathrm{PGF}_{2 \alpha}, 15-k$ eto-PGF $2 \alpha, 15-\mathrm{F}_{1 \mathrm{t}^{-}}$

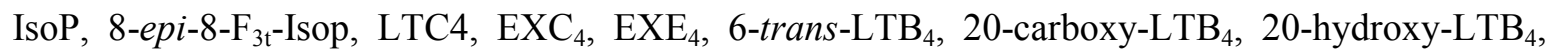
and 13, 14-dihydro-15-keto PGE $_{1}$ ) were not detected.

\section{Prostaglandin and thromboxane metabolites derived from Arachidonic acid}

Recent publications have demonstrated changes in lipid peroxidation as a consequence of chronic exercise. ${ }^{5-8}$ A prior study by our group showed a decrease in the values of urinary PGs (tetranor-PGEM and 11- $\beta-\mathrm{PGF}_{2 \alpha}$ ) after a chronic training program. ${ }^{5}$ Our current results are similar, showing a decline in these biomarkers due to the elite training program. In our urine samples, 17 PGs from different families were quantified. Our data show means in the range from $0.04 \pm 0.08 \mu \mathrm{g}$ $24 \mathrm{~h}^{-1}\left(\mathrm{PGE}_{2}\right)$ to $41.2 \pm 24.4 \mu \mathrm{g} 24 \mathrm{~h}^{-1}$ (PGDM). The PGs are potent oxylipins involved in numerous homeostatic biological functions and inflammation. ${ }^{18}$ The literature mentions that regular exercise induces an anti-inflammatory response rather than a pro-inflammatory response. ${ }^{4,9}$ In this context, 
284 the results for the concentrations of metabolites from the $\mathrm{PGD}_{2}$ pathway are notable since they have 285 been implicated in both the development and resolution of inflammation. For the $\mathrm{PGD}_{2}$ pathway, 286 the Friedman test revealed statistically significant differences $\left(\chi^{2}(4)=42.143, P<0.001\right)$. The CP-T 287 value was significantly lower, compared to all other stages (Figure 3, A). Moreover, without the 288 Bonferroni correction, the ACJ stage was different from $\mathrm{C}-\mathrm{T}(\mathrm{Z}=-2.155, P=0.031)$. Individually and 289 concerning the $\mathrm{PGD}_{2}$ metabolites, PGDM was the metabolite that showed the highest excretion 290 levels. Prostaglandin $\mathrm{D}_{2}$ is a COX product of AA that activates D prostanoid receptors to modulate 291 vascular, platelet, and leukocyte function in vitro. ${ }^{51}$ The Friedman test revealed statistically 292 significant changes (Table 3) in this metabolite; the Wilcoxon test showed that the CP-T value was 293 lower than for $\mathrm{C}-\mathrm{T}(\mathrm{Z}=-3.237, P<0.001)$. The $11-\beta-\mathrm{PGF}_{2 \alpha}$ content in the CP-T stage was 294 significantly lower than in all other stages $(\mathrm{CB}, \mathrm{Z}=-3.124, P=0.002$; $\mathrm{C}-\mathrm{T}, \mathrm{Z}=-3.124, P<0.001$; 295 placebo, $\mathrm{Z}=-3.237, P=0.001$; and $\mathrm{ACJ}, \mathrm{Z}=-3.067, P=0.002)$. The 2, 3-dinor-11- $\beta-\mathrm{PGF}_{2 \alpha}$ excretion in 296 the ACJ stage was lower than for $\mathrm{C}-\mathrm{B}(\mathrm{Z}=-2.953, P=0.003)$ and $\mathrm{C}-\mathrm{T}(\mathrm{Z}=-3.124, P=0.002)$. The ACJ 297 stage also showed a lower value of this compound compared to the placebo stage, though this was 298 299 300 $(\mathrm{Z}=-3.233, P=0.001)$, and $\mathrm{ACJ}(\mathrm{Z}=-2.856, P=0.004)$ (Table 3$)$. According to research carried out by 301 Morrow et al., ${ }^{52} \mathrm{PGDM}$ is a major urinary metabolite of $\mathrm{PGD}_{2}$ with a unique lower side-chain that 302 readily undergoes reversible cyclization. In our study, the urinary excretion of PGDM was highest under basal conditions, but showed a decreased about $70 \%$ by the end of the experiment. This suggests that in our triathletes there was a reduction in the inflammation status since the hallmark of 305 inflammation is the enhanced secretion of pro-inflammatory immune mediators such as PGs. ${ }^{49,53} \mathrm{~A}$ study in humans using liquid chromatography-tandem mass spectrometry mentioned that tetranorPGDM was much more abundant than the $\mathrm{PGD}_{2}$ metabolites $11 \beta-\mathrm{PGF}_{2 \alpha}$ and 2, 3-dinor-11 $\beta-\mathrm{PGF}_{2 \alpha}$ 308 in the urine of healthy volunteers. ${ }^{51}$ In our elite triathletes, $11_{\beta}-\mathrm{PGF}_{2 \alpha}$ and 2, 3-dinor- $11_{\beta}-\mathrm{PGF} \mathrm{F}_{2 \alpha}(\mathrm{F}-$ 309 ring metabolites) were much more abundant than tetranor-PGDM (D-ring metabolite). This leads us 
310

311

312

313

314

315

316

317

318

319

320

321

322

323

324

325

326

327

328

329

330

331

332

333

334

to believe that physical exercise affects quantitatively the excretion of metabolites of this PGD pathway, when compared to non-athletes volunteers. Concerning the effect of ACJ intake on the excretion of $\mathrm{PGD}_{2}$ metabolites, we observed a positive influence, since 2, 3-dinor-11 $\beta-\mathrm{PGF}_{2 \alpha}$ showed a significant decrease when compared to the first controls; also, the excretion of PGDM showed a significant reduction (in the placebo stage it remained constant). Previous studies, both in vivo and in vitro, have also reported some influence on the cardiovascular system due to supplementation in the diet of polyphenols. ${ }^{1,13,47}$ In addition, a study by our group analyzed the biomarker implicated in iron metabolism, hepcidin, and revealed that long-term training using ECOs reduces inflammation and, hence, could be responsible for the decrease in hepcidin in triathletes found in this study. ${ }^{54}$

Metabolites from the PGE pathway showed a significant decrease after increased training, suggesting that physical exercise also played a role in the decline in excretion of these metabolites. The metabolites of the $\mathrm{PGE}_{2}$ pathway in C-B and C-T was higher, but subsequently fell ( $\chi^{2}$ (4) $=21.962, P=0.001$ ) (Figure 3, A). As well, we cannot rule out an effect of ACJ intake on inflammation since the excretion of $\mathrm{PGE}_{2}$ (detected in all periods) increased in comparison to the placebo stage $(0.04 \pm 0.08$ vs. $0.19 \pm 0.30)$. The placebo period showed lower values than $\mathrm{C}-\mathrm{B}(\mathrm{Z}=-$ 2.98, $P=0.003)$ and $\mathrm{C}-\mathrm{T}(\mathrm{Z}=-3.180, P=0.001)$, although the excretion values did not decrease significantly between $\mathrm{C}-\mathrm{B}$ and $\mathrm{C}-\mathrm{T}(\mathrm{Z}=-2.669, P=0.008)$. The other three metabolites of the $\mathrm{E}$ pathway (20-OH-PGE 2 , tetranor-PGEM, and tetranor-PGAM) were mainly detected in the two control periods (C-B and C-T), but in the beverage intake stages and the CP-T stage the number of volunteers that excreted these biomarkers decreased. The $20-\mathrm{OH}-\mathrm{PGE}_{2}$ was excreted by the majority of the volunteers after the juice intake, compared to the placebo. $\mathrm{PGE}_{2}$ is involved in all processes leading to the classic signs of inflammation (redness, swelling, and pain), but also shows anti-inflammatory properties. ${ }^{18}$ For example, according to recent in vivo studies, this lipid mediator is related to numerous physiological and pathophysiological processes in the kidney, ${ }^{55}$ involving a 
significant role in modulating the effect of vasopressin on the osmotic water reabsorption in the renal collecting duct cells - where it attenuates antidiuretic action. ${ }^{56}$ In addition, it has been mentioned that the induction of prostanoids during exercise alters clotting factors, increases vascular tone, and helps adapt muscle cells to contractile activity. ${ }^{57}$ Based on the above, our results suggest a potential effect of ACJ intake on the inflammatory process and vascular system.

Regarding the F and I pathways, the metabolites were scarcely detected in the urine samples or did not differ significantly during the study. Concerning the TXs, the primary enzymatic metabolite of $\mathrm{TXA}_{2}$ is $11-\mathrm{dh}-\mathrm{TXB}_{2}$, which has been validated as a reliable and noninvasive biomarker-integrated index of in vivo platelet activation ${ }^{58}$. A previous report observed that 22 sedentary subjected to standardized, aerobic, high-amount-high-intensity training for eight weeks showed significant decreases in the urinary excretion of $11-\mathrm{dh}-\mathrm{TXB}_{2} .{ }^{59}$ The authors related this result to platelet activation and hence it may be relevant to explain why long-term physical exercise is beneficial for the cardiovascular system. According to our results, the excretion of $11-\mathrm{dh}-\mathrm{TxB}_{2}$ showed a significant decrease in the ACJ $(Z=-2.953, P=0.003)$ and CP-T $(Z=-3.069, P=0.002)$ stages, compared to C-T (Table 3). The 11-dh- $\mathrm{TXB}_{2}$ decreased significantly in the last period when the training load was lower; ACJ also had a considerable influence, reducing the values, suggesting a cardiovascular benefit.

\section{Leukotrienes}

Two metabolites $\left(\mathrm{LTB}_{4}\right.$ and $\left.\mathrm{LTE}_{4}\right)$ were detected in all stages and in the majority of the volunteers. The Friedman test showed significant changes in $\mathrm{LTB}_{4}$ and the subsequent Wilcoxon signed-rank test revealed higher values in the ACJ stage compared with the placebo $(Z=-2.166$, $P=0.03), \mathrm{C}-\mathrm{T}(\mathrm{Z}=-2.668, P=0.008)$, and $\mathrm{CP}-\mathrm{T}(\mathrm{Z}=-2.166, P=0.03)$ stages. However, no $P$-value was below 0.005 . Contrarily, $\mathrm{LTE}_{4}$ showed a significant decrease in the placebo stage, relative to the baseline values $(\mathrm{Z}=-2.784, P=0.005)$. Also, the placebo stage differed from the ACJ stage $(\mathrm{Z}=$ - 

statistically so (Table 3). In summary, the urinary metabolites $\mathrm{LTB}_{4}$ and $\mathrm{LTE}_{4}$ showed significant changes; in particular, the ACJ stage presented higher values than the placebo phase. These findings are the opposite of those mentioned in the current literature, since most polyphenols-intake studies have shown decreased excretion in healthy people. ${ }^{50,60}$ It has been demonstrated that flavonoids can modulate the activity of enzymes that are involved in the metabolism of AA in macrophages such as phospholipase $\mathrm{A}_{2}, \mathrm{COXs}$, and LOXs; inhibition of these enzymes by flavonoids lowers the production of the mediators of inflammatory reactions. ${ }^{60}$ Yoon and Baek, $2005{ }^{61}$ mentioned also that polyphenols are inhibitors of both COX and LOX and that a general rule is "more COX inhibitions and less LOX inhibitions with polyphenols that contain few hydroxyl substituents (with none in ring B)". This suggests that polyphenols, including those in our juice rich in polyphenols, have more effect on an inflammatory cascade of COX-2, which allows the LOX branch to accelerate the formation of LTs. This explanation seems to describe to a certain extent the change produced in the excretion values in our study. On the other hand, due to the decline in the ECOs load, a decrease in the excretion of $\mathrm{LTE}_{4}$ was detected. Other reports have mentioned that elite athletes show an increased risk of respiratory symptoms related to asthma, especially those that

377 participate in endurance sports - such as swimming, running, and cycling - and in winter sports.

378 This risk to the respiratory system arises because, during physical activity, the elite athletes increase 379 their water and heat loss through respiration. ${ }^{62}$ This has strong ties with the LTs results since they 380 play a key role in perpetuating airway inflammation - leading directly to airflow obstruction through 381 the effects on vascular permeability, mucus production, and smooth muscle constriction. ${ }^{63} \mathrm{~A}$ 382 training program can result in a depletion of LTs and/or a slow cys-LTs response to exercise, which 383 may be responsible for the protective effect of training programs on respiratory symptoms. ${ }^{64}$ Our 384 study shows that post-training could change the excretion of cys-LTs, and therefore might have an 385 effect on the airway pathway. 
389 The measurement of $\mathrm{F}_{2}$-IsoPs is known to be an index of OS in vivo. ${ }^{14}$ Regarding the level of total 390 IsoPs derived from AA in urine, a significant reduction was observed; reflecting mainly the OS 391 decrease in the CP-T stage (Figure 3, C). When the sum of all the IsoPs was submitted to the 392 Friedman test, a significant $P$-value $\left(\chi^{2}(4)=91.035, P \leq 0.001\right)$ was obtained. The total IsoPs ranged 393 from $6.10 \pm 6.47 \mu \mathrm{g} 24 \mathrm{~h}^{-1}(\mathrm{C}-\mathrm{B})$ to $3.42 \pm 5.9 \mu \mathrm{g} 24 \mathrm{~h}^{-1}(\mathrm{CP}-\mathrm{T})$. The Wilcoxon signed-rank test 394 showed a tendency of the excretion to fall over the study (Figure 3, C). The IsoPs showed 395 significant variation in their urinary excretion when the values were analyzed by series: $15-\mathrm{F}_{2 \mathrm{t}}$-IsoPs $\left(\chi^{2}(4)=33.360, P \leq 0.001\right), 5-\mathrm{F}_{2 \mathrm{t}}-\mathrm{IsoPs}\left(\chi^{2}(4)=12.893, P=0.012\right)$, and $15-\mathrm{E}_{2}-\mathrm{IsoPs}\left(\chi^{2}(4)=14.484\right.$, $P=0.006$ ) (Figure 3, B).

These data suggest that chronic exercise decreased OS levels in our elite athletes. 399 According to the review by Nikolaidis et al., ${ }^{65}$ in most of the cases in which they analyzed this 400 behavior the levels of urinary $\mathrm{F}_{2}$-IsoP were decreased by chronic exercise. In other studies, ${ }^{5,62-64}$ 401 physical activity also was the primary factor that decreased the urinary OS biomarker (IsoPs). The literature mentions that regular exercise training increases the levels of enzymatic and nonenzymatic antioxidants in muscle fibers, resulting in improved endogenous protection against 404 exercise-mediated oxidative damage. ${ }^{10}$ Furthermore, in athletes of different disciplines, 405 polyphenols have shown an antioxidant potential that can be beneficial in the reduction of oxidative 406 damage effects during intense exercise. ${ }^{4}$ In our study, considering the metabolites individually, we 407 observed an increase in 15-epi-15- $\mathrm{E}_{2 \mathrm{t}}-\mathrm{IsoP}$ and $15-\mathrm{keto}-15-\mathrm{F}_{2 \mathrm{t}}-\mathrm{IsoP}$, but this change was not linked 408 to physical exercise directly since the increase was in the ACJ stage, when compared to the placebo. 409 This result suggests a potential role for the compounds from ACJ intake in these IsoP pathways. 410 Recent reports have shown that the E-type IsoPs are potent vasoconstrictors at low nanomolar 411 concentrations. ${ }^{41} 15-\mathrm{E}_{2 \mathrm{t}}$-IsoP (also referred to as 8 -iso-PGE 2 or iPE2-III) was found to be a 
412 powerful and efficient constrictor in the ductus arteriosus of chicken, acting through the

413 thromboxane receptor. ${ }^{68}$ Also, other studies with animals have shown both vasoconstrictive and 414 vasodilatory effects of $15-\mathrm{E}_{2 \mathrm{t}}$-IsoP, suggesting biological activity of this molecule in the

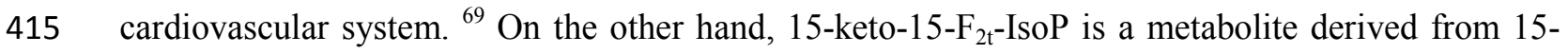
$416 \quad \mathrm{~F}_{2 \mathrm{t}}$-IsoP. In an animal study, it was demonstrated that this IsoP probably acted as a partial agonist at 417 the TP-receptor, mediating contraction and inducing a weak endothelium-independent relaxation at 418 high concentrations. ${ }^{70}$ Therefore, the increase in abundance of these metabolites could reflect 419 participation of the compounds from ACJ - for example, the flavonoids (polyphenols) ${ }^{71}$ - or of 420 proline betaine, ferulic acid, or other metabolic derivatives (nutritional biomarkers) ${ }^{72}$ in the 421 stimulation of some IsoPs related to the effects on vascular smooth muscle. Also, it should not be 422 forgotten that, as well as phytochemicals, ACJ contains a variety of vitamins, minerals, and fiber 423 that could have influenced this result. ${ }^{73,74}$

Metabolites derived from Eicosapentaenoic acid and Dihomo- $\gamma$-linolenic acid revealed significant changes among the experimental periods $\left(\chi^{2}(3)=29.624, P \leq 0.001\right)$. The Wilcoxon test showed that the CP-T value was significantly lower (C-T, Z=-3.408; placebo, $\mathrm{Z}=3.294$; ACJ, $\mathrm{Z}=-3.324, P=0.001$ in all cases) compared to most of the other stages (Table 3). According to the literature, through a series of free radical reactions, COX metabolizes DGLA and AA to form various bioactive metabolites - namely, the 1 and the 2 series of prostaglandins (PG1 and PG2), respectively. Unlike the PG2s, which are viewed as pro-inflammatory, the PG1s possess

434 anti-inflammatory and anticancer activity. ${ }^{19}$ During our study, PGE $_{1}$ was detected in all stages, 435 showing statistically significant differences (Table 3). These results suggest a decrease in this 436 metabolite in urine when there is a decline in ECOs, although the values during C-T were higher 437 than in $\mathrm{C}-\mathrm{B}$, since the acute physical exercise could have stimulated this pathway. $\mathrm{PGE}_{1}$ has been 
438 shown to possess anti-inflammatory properties and to modulate vascular reactivity. ${ }^{75}$ On the other 439 hand, 15- $\mathrm{E}_{1 \mathrm{t}}$-IsoP was mainly detected in C-B $\left(0.5 \pm 0.1 \mu \mathrm{g} 24 \mathrm{~h}^{-1}\right)$, suggesting that physical exercise 440 is an external factor that could have influenced the diminution of its values. IsoP was detected only during C-B $\left(3.4 \pm 2.3 \mu \mathrm{g} 24 \mathrm{~h}^{-1}\right)$. The elite training decreased the values of

444 8- $\mathrm{F}_{3 \mathrm{t}}$-IsoP, suggesting again that physical exercise is an external factor that could influence the 445 reduction of biomarkers concomitantly with the decline in the training loads of the athletes (CP-T).

446 These IsoPs are formed by the free radical-induced peroxidation of EPA in vivo and in vitro. The

$447 \quad \mathrm{~F}_{3}$-IsoPs are spontaneously generated in abundance in situ in response to OS and both are useful as 448 biomarkers of OS. ${ }^{23,76}$

\section{Conclusions}

This study contributes to a better comprehension of the behavior of urinary biomarkers related to OS and inflammation status (IsoPs, LTs, PGs, and TXs) in athletes after an elite training

454 period and supplementation of $200 \mathrm{~mL}$ of ACJ (a functional beverage rich in polyphenols). The 455 findings indicate that physical exercise is an external factor that influenced mainly the OS 456 biomarkers $\left(\mathrm{F}_{2}\right.$-IsoPs) and inflammation biomarkers (11-dh-TxB $2, \mathrm{PGE}_{2}, \mathrm{PGDM}$, tetranor-PGFM, $457 \mathrm{PGF}_{1 \alpha}, \mathrm{PGE}_{1}$, and $\left.\mathrm{LTE}_{4}\right)$ in triathletes. Furthermore, our collective results regarding ACJ intake 458 show that supplementation stimulated the excretion of some metabolites related to vascular 459 homeostasis and smooth muscle (15-epi-15-E 2 -IsoPs, 15-keto-F $\mathrm{F}_{2 \mathrm{t}} \mathrm{IsoP}, 20-\mathrm{OH}-\mathrm{PGE}_{2}, \mathrm{PGE}_{2}, \mathrm{LTE}_{4}$, 460 and $\mathrm{LTB}_{4}$ ), indicating a potential role in the cardiovascular system. This work could help to increase 461 our knowledge about the effect of chronic exercise and sports drinks on human lipid metabolism.

462 Moreover, it could aid the design of new beverages for athletes. 


\section{Acknowledgments and declaration of interest sections}

464

465

This study was supported by the Project AGL2011-23690 (CICYT) (Spanish Ministry of Economy and Competitiveness). This work was partially funded by the "Fundación Séneca de la Región de Murcia" Grupo de Excelencia 19900/GERM/15. This work is included in the framework of the collaboration between the Spanish Research Council (CEBAS-CSIC) and CNRS-University of Montpellier as "Projets Internationaux de Cooperation Scientifique (PICS-2015-261141). LAGF was granted a pre-doctoral FPI fellowship by the Spanish government as well as a scholarship that allowed the collaboration with Dr. Craig Wheelock's group (Department of Medical Biochemistry and Biophysics (MBB)) at the Karolinska Institute. The authors are also grateful to the University of Alicante for its collaboration. Sonia Medina was appointed under a research contract from the Project AGL2011-23690 (CICYT).

475 The authors declare that they have no conflict of interest.

\section{Author Contribution}

477 LA García-Flores carried out the analytical processes and wrote and discussed the present paper. S 478 Medina, C Gómez, and C Wheelock supervised the analytical processes and developed the 479 discussion of the paper. R Cejuela (coach) monitored the physical exercise training of the triathletes. J M Martínez-Sanz was nutritionist of the triathletes and monitored the nutritional plan.

481 C Oger, Jean-Marie Galano, and Thierry Durand provided the markers for the study and helped 482 with the review of the manuscript. A Hernández-Sáez helped to the analytical processes. Federico 483 Ferreres helped with the experimental procedures linked to UHPLC-QqQ-MS/MS. Ángel Gil484 Izquierdo and Sonia Medina designed, supervised, and discussed this research work. 


\section{Figure captions}

489

Figure 1 Flow chart: pathway of the oxylipins analyzed in this study. The metabolites nomenclature

490 is described in the text.

491

Figure 2 Study design: this crossover study was randomized, double-blind, and placebo-controlled.

492 Sixteen athletes, randomly divided into two groups, were assigned to supplementation of either 200

493 $\mathrm{mL}$ of ACJ or $200 \mathrm{~mL}$ of placebo. After 45 days of supplementation and a 10-day washout period,

494 the beverages were reversed. Three controls were used: baseline control, control training, and control post-training with duration of 15 days. Urine samples were collected at the end of each stage. The training load quantification was by the Objective Load Scale (ECOs). ${ }^{5,33,36}$

Figure 3 Box plots with quartiles (upper values $75 \%$, median $50 \%$, and lower values $25 \%$ ) of the $\mathrm{P}<0.005$ with Bonferroni correction $(* *=\mathrm{P}<0.005$ and $* * *=\mathrm{P}<0.001)$. A) Prostaglandins by

502

503

504

505

506

507

508

509

510

511 


\section{References}

1. K. H. Myburgh, Polyphenol supplementation: benefits for exercise performance or oxidative stress?, Sports Med (Auckland, N.Z.), 2014, 44 Suppl 1, S57-70.

2. T. T. Peternelj and J. S. Coombes, Antioxidant supplementation during exercise training: beneficial or detrimental?, Sports Med(Auckland, N.Z.), 2011, 41, 1043-1069.

3. J. M. Morillas-Ruiz, J. A. Villegas Garcia, F. J. Lopez, M. L. Vidal-Guevara and P. Zafrilla, Effects of polyphenolic antioxidants on exercise-induced oxidative stress, Clinical Nut (Edinburgh, Scotland), 2006, 25, 444-453.

4. A. Sureda, S. Tejada, M. Bibiloni Mdel, J. A. Tur and A. Pons, Polyphenols: well beyond the antioxidant capacity: polyphenol supplementation and exercise-induced oxidative stress and inflammation, Current Pharma Biotech, 2014, 15, 373-379.

5. S. Medina, R. Dominguez-Perles, R. Cejuela-Anta, D. Villano, J. M. Martinez-Sanz, P. Gil, C. Garcia-Viguera, F. Ferreres, J. I. Gil and A. Gil-Izquierdo, Assessment of oxidative stress markers and prostaglandins after chronic training of triathletes, Prostaglandins Other Lipid Mediat, 2012, 99, 79-86.

6. S. Lafay, C. Jan, K. Nardon, B. Lemaire, A. Ibarra, M. Roller, M. Houvenaeghel, C. Juhel and L. Cara, Grape extract improves antioxidant status and physical performance in elite male athletes, $J$ Sports Sci Med, 2009, 8, 468-480.

7. E. I. Varamenti, A. Kyparos, A. S. Veskoukis, M. Bakou, S. Kalaboka, A. Z. Jamurtas, Y. Koutedakis and D. Kouretas, Oxidative stress, inflammation and angiogenesis markers in elite female water polo athletes throughout a season, Food Chem Toxicol, 2013, 61, 3-8.

8. A. J. Braakhuis, W. G. Hopkins and T. E. Lowe, Effects of dietary antioxidants on training and performance in female runners, Eur J Sport Sci, 2014, 14, 160-168.

9. A. M. Petersen and B. K. Pedersen, The anti-inflammatory effect of exercise, $J$ Appl Physiol (1985), 2005, 98, 1154-1162.

10. S. J. Stear, L. M. Burke and L. M. Castell, BJSM reviews: A-Z of nutritional supplements: dietary supplements, sports nutrition foods and Ergogenic aids for health and performance Part 3, British J Sport Med, 2009, 43, 890-892.

11. N. A. Lewis, G. Howatson, K. Morton, J. Hill and C. R. Pedlar, Alterations in redox homeostasis in the elite endurance athlete, Sport Med (Auckland, N.Z.), 2015, 45, 379-409.

12. D. C. Nieman and S. H. Mitmesser, Potential Impact of Nutrition on Immune System Recovery from Heavy Exertion: A Metabolomics Perspective, Nutrients, 2017, 9, 513.

13. D. Balgoma, A. Checa, D. G. Sar, S. Snowden and C. E. Wheelock, Quantitative metabolic profiling of lipid mediators, Molecular Nut\& Food Res, 2013, 57, 1359-1377.

14. M. C. Noverr, J. R. Erb-Downward and G. B. Huffnagle, Production of Eicosanoids and Other Oxylipins by Pathogenic Eukaryotic Microbes, Clin Microbio Rev, 2003, 16, 517 533.

15. M. Malaguti, C. Angeloni and S. Hrelia, Polyphenols in Exercise Performance and Prevention of Exercise-Induced Muscle Damage, Oxi Medi Cell Longev, 2013, 2013, 9.

16. L. J. Roberts and J. D. Morrow, Measurement of F(2)-isoprostanes as an index of oxidative stress in vivo, Free Radical Biol Med, 2000, 28, 505-513.

17. C. D. Funk, Prostaglandins and leukotrienes: advances in eicosanoid biology, Science (New York, N.Y.), 2001, 294, 1871-1875.

18. E. Ricciotti and G. A. FitzGerald, Prostaglandins and inflammation, Arterioscler Thromb Vasc Biol, 2011, 31, 986-1000.

19. X. Wang, Y. Lin H Fau - Gu and Y. Gu, Multiple roles of dihomo-gamma-linolenic acid against proliferation diseases, Lipid Health Dis 2012, 11: 25.

20. R. C. Murphy and M. A. Gijon, Biosynthesis and metabolism of leukotrienes, Biochem J, 2007, 405, 379-395. 
610

611

612

21. G. L. Milne, H. Yin, K. D. Hardy, S. S. Davies and L. J. Roberts, 2nd, Isoprostane generation and function, Chem Rev, 2011, 111, 5973-5996.

22. K. Svanborg, M. Bygdeman and P. Eneroth, The F and 19-hydroxy F prostaglandins and their $8 \beta$-isomers in human seminal plasma: Data on chromatography and mass spectrometry, Biol Mass Spectro, 1983, 10, 495-498.

23. L. Gao, H. Yin, G. L. Milne, N. A. Porter and J. D. Morrow, Formation of F-ring isoprostane-like compounds (F3-isoprostanes) in vivo from eicosapentaenoic acid, $J$ Biol Chem, 2006, 281, 14092-14099.

24. R. Imbusch and M. J. Mueller, Formation of isoprostane F2-like compounds (phytoprostanes F1) from $\alpha$-linolenic acid in plants, Free Radical Biol Med, 2000, 28, 720 726.

25. W. L. Smith, Cyclooxygenases, peroxide tone and the allure of fish oil, Current $O$ Cell Biol, 2005, 17, 174-182.

26. M. L. M. Cabañas-Armesilla MD, Herrero de Lucas A., in Introducción de la técnica antropométrica. Método., ed. C. d. Cineantropometría., Editores. CTO, Madrid, 2009.

27. J. R. Alvero Ramón, M.D. Cabañas-Armesilla; A. Herrero de Lucas; L. Martínez Riaza; C. Moreno Pascua; J. Porta Manzañido; M. Sillero Quintana; J.E Sirvent Belando, Protocolo de valoración de la composición corporal para el reconocimiento médicodeportivo. Documento de Consenso del Grupo Español de Cineantropometría (GREC) de la Federación Española de Medicina del Deporte (FEMEDF), Archiv Med Dep 2010, 27, 330334.

28. R. T. Withers, N. P. Craig, P. C. Bourdon and K. I. Norton, Relative body fat and anthropometric prediction of body density of male athletes, Europ J Appl Physio., 1987, 56, 191-200.

29. R. C. Lee, Z. Wang, M. Heo, R. Ross, I. Janssen and S. B. Heymsfield, Total-body skeletal muscle mass: development and cross-validation of anthropometric prediction models, The Ame J Clin Nut, 2000, 72, 796-803.

30. B. E. Ainsworth, W. L. Haskell, M. C. Whitt, M. L. Irwin, A. M. Swartz, S. J. Strath, W. L. O'Brien, D. R. Bassett, Jr., K. H. Schmitz, P. O. Emplaincourt, D. R. Jacobs, Jr. and A. S. Leon, Compendium of physical activities: an update of activity codes and MET intensities, Med Sci Sport Exer, 2000, 32, S498-504.

31. A. E. Jeukendrup, R. L. Jentjens and L. Moseley, Nutritional considerations in triathlon, Sport Med (Auckland, N.Z.), 2005, 35, 163-181.

32. E. Gonzalez-Molina, D. A. Moreno and C. Garcia-Viguera, Aronia-enriched lemon juice: a new highly antioxidant beverage, J Agri Food Chem, 2008, 56, 11327-11333.

33. L. A. Garcia-Flores, S. Medina, R. Cejuela-Anta, J. M. Martinez-Sanz, A. Abellan, H.-G. Genieser, F. Ferreres and A. Gil-Izquierdo, DNA catabolites in triathletes: effects of supplementation with an aronia-citrus juice (polyphenols-rich juice), Food Funct, 2016, 7, 2084-2093.

34. L. A. Garcia-Flores, S. Medina, C. Oger, J.-M. Galano, T. Durand, R. Cejuela, J. M. Martinez-Sanz, F. Ferreres and A. Gil-Izquierdo, Lipidomic approach in young adult triathletes: effect of supplementation with a polyphenols-rich juice on neuroprostane and F2-dihomo-isoprostane markers, Food Funct, 2016, 7, 4343-4355.

35. R. Cejuela-Anta and J. Esteve-Lanao, Training load quantification in triathlon, J Human Sport Exer 2011, 6, 218-232.

36. S. Medina, R. Domínguez-Perles, C. García-Viguera, R. Cejuela-Anta, J. M. MartínezSanz, F. Ferreres and A. Gil-Izquierdo, Physical activity increases the bioavailability of flavanones after dietary aronia-citrus juice intake in triathletes, Food Chem, 2012, 135, 2133-2137.

37. J. Borresen and M. I. Lambert, The quantification of training load, the training response and the effect on performance, Sports Med (Auckland, N.Z.), 2009, 39, 779-795. 
613 38. McGraw-Hill, Concise Dictionary of Modern Medicine, 2002.

614 39. S. Lorna, Clinical Trials: What Patients and Volunteers Need to Know USA . Oxford University Press, 1st ed. edn., 2010.

40. T. Durand, J.-L. Cracowski, A. Guy and J.-C. Rossi, Syntheses and preliminary pharmacological evaluation of the two epimers of the 5-F2t-isoprostane, Bioorg Med Chem Lett, 2001, 11, 2495-2498.

41. Y. Brinkmann, C. Oger, A. Guy, T. Durand and J.-M. Galano, Total Synthesis of 15-D2tand 15-epi-15-E2t-Isoprostanes, J Org Chem, 2010, 75, 2411-2414.

42. T. Durand, A. Guy, J.-P. Vidal and J.-C. Rossi, Total Synthesis of (15R)- and (15S)-F2tIsoprostanes by a Biomimetic Process Using the Cyclization of Acyclic Dihydroxylated Octa-5,7-dienyl Radicals, J Org Chem, 2002, 67, 3615-3624.

43. A. Guy, T. Durand, A. Roland, E. Cormenier and J.-C. Rossi, Total synthesis of ent15(RS)-2,3-dinor-5,6-dihydro-8-epi-PGF2 $\alpha$, Tetrahedron Lett, 1998, 39, 6181-6184.

44. A. Guy, C. Oger, J. Heppekausen, C. Signorini, C. De Felice, A. Fürstner, T. Durand and J.M. Galano, Oxygenated Metabolites of n-3 Polyunsaturated Fatty Acids as Potential Oxidative Stress Biomarkers: Total Synthesis of 8-F3t-IsoP, 10-F4t-NeuroP and [D4]-10F4t-NeuroP, Chem - Euro J, 2014, 20, 6374-6380.

45. D. Balgoma, J. Larsson, J. Rokach, J. A. Lawson, K. Daham, B. Dahlen, S. E. Dahlen and C. E. Wheelock, Quantification of lipid mediator metabolites in human urine from asthma patients by electrospray ionization mass spectrometry: controlling matrix effects, Anal Chem, 2013, 85, 7866-7874.

46. S. Medina, R. Dominguez-Perles, J. I. Gil, F. Ferreres, C. Garcia-Viguera, J. M. MartinezSanz and A. Gil-Izquierdo, A ultra-pressure liquid chromatography/triple quadrupole tandem mass spectrometry method for the analysis of 13 eicosanoids in human urine and quantitative 24 hour values in healthy volunteers in a controlled constant diet, Rapid Commun Mass Spectrom, 2012, 26, 1249-1257.

47. B. K. Matuszewski, M. L. Constanzer and C. M. Chavez-Eng, Strategies for the Assessment of Matrix Effect in Quantitative Bioanalytical Methods Based on HPLC-MS/MS, Analytical Chem, 2003, 75, 3019-3030.

48. FDA, U.S. Department of Health and Human Services Food and Drug Administration (2001) Guiadance for Industry: bioanalytical method validation, http://www.fda.gov/downloads/Drugs/Guidances).

49. K. Appel, P. Meiser, E. Millan, J. A. Collado, T. Rose, C. C. Gras, R. Carle and E. Munoz, Chokeberry (Aronia melanocarpa (Michx.) Elliot) concentrate inhibits NF-kappaB and synergizes with selenium to inhibit the release of pro-inflammatory mediators in macrophages, Fitoterapia, 2015, 105, 73-82.

50. J. F. Reis, V. V. S. Monteiro, R. de Souza Gomes, M. M. do Carmo, G. V. da Costa, P. C. Ribera and M. C. Monteiro, Action mechanism and cardiovascular effect of anthocyanins: a systematic review of animal and human studies, J TransMed, 2016, 14, 315.

51. W. L. Song, M. Wang, E. Ricciotti, S. Fries, Y. Yu, T. Grosser, M. Reilly, J. A. Lawson and G. A. FitzGerald, Tetranor PGDM, an abundant urinary metabolite reflects biosynthesis of prostaglandin D2 in mice and humans, J Biol Chem, 2008, 283, 1179-1188.

52. J. D. Morrow, C. Prakash, J. A. Awad, T. A. Duckworth, W. E. Zackert, I. A. Blair, J. A. Oates and L. J. Roberts, 2nd, Quantification of the major urinary metabolite of prostaglandin D2 by a stable isotope dilution mass spectrometric assay, Anal Biochem, 1991, 193, 142-148.

53. G. Astarita, A. C. Kendall, E. A. Dennis and A. Nicolaou, Targeted lipidomic strategies for oxygenated metabolites of polyunsaturated fatty acids, Biochimica et biophysica acta, 2015, 1851, 456-468. 
54. D. Villaño, C. Vilaplana, S. Medina, F. Algaba-Chueca, R. Cejuela-Anta, J. Martínez-Sanz, F. Ferreres and A. Gil-Izquierdo, Relationship between the Ingestion of a Polyphenol-Rich Drink, Hepcidin Hormone, and Long-Term Training, Molecules, 2016, 21, 1333.

55. E. T. Olesen and R. A. Fenton, Is there a role for PGE2 in urinary concentration?, $J$ Ame Soc Nephro : JASN, 2013, 24, 169-178.

56. R. Nørregaard, T.-H. Kwon and J. Frøkiær, Physiology and pathophysiology of cyclooxygenase-2 and prostaglandin E2 in the kidney, Kidney Res Clin Pract, 2015, 34, 194-200.

57. M. Blatnik and R. C. Steenwyk, Quantification of urinary PGEm, 6-keto PGF(1alpha) and 2,3-dinor-6-keto PGF(1alpha) by UFLC-MS/MS before and after exercise, Prostaglandins Other Lipid Mediat, 2010, 93, 8-13.

58. G. Davi and C. Patrono, Platelet activation and atherothrombosis, New Eng J Med, 2007, 357, 2482-2494.

59. F. Santilli, N. Vazzana, P. Iodice, S. Lattanzio, R. Liani, R. G. Bellomo, G. Lessiani, F. Perego, R. Saggini and G. Davi, Effects of high-amount-high-intensity exercise on in vivo platelet activation: modulation by lipid peroxidation and AGE/RAGE axis, Thrombo Haemo, 2013, 110, 1232-1240.

60. P. C. Hollman, A. Cassidy, B. Comte, M. Heinonen, M. Richelle, E. Richling, M. Serafini, A. Scalbert, H. Sies and S. Vidry, The biological relevance of direct antioxidant effects of polyphenols for cardiovascular health in humans is not established, $J N u t, 2011,141,989 \mathrm{~S}-$ 1009S.

61. J.-H. Yoon and S. J. Baek, Molecular Targets of Dietary Polyphenols with Antiinflammatory Properties, Yonsei Med J, 2005, 46, 585-596.

62. S. R. D. Giacco, D. Firinu, L. Bjermer and K.-H. Carlsen, Exercise and asthma: an overview, Europ Clini Resp J, 2015, 2, 10.3402/ecrj.v3402.27984.

63. T. S. Hallstrand and W. R. Henderson, Jr., Role of leukotrienes in exercise-induced bronchoconstriction, Currt Allerg Asth Rep, 2009, 9, 18-25.

64. I. M. El-Akkary, Z. E.-K. Abdel-Fatah, M. E.-S. El-Seweify, G. A. El-Batouti, E. A. Aziz and A. I. Adam, Role of leukotrienes in exercise-induced bronchoconstriction before and after a pilot rehabilitation training program, Intern J Gen Med, 2013, 6, 631-636.

65. M. G. Nikolaidis, A. Kyparos and I. S. Vrabas, F2-isoprostane formation, measurement and interpretation: The role of exercise, Progress Lipid Res, 2011, 50, 89-103.

66. M. J. Jackson, Free radicals in skin and muscle: damaging agents or signals for adaptation?, Procee Nut Soc, 1999, 58, 673-676.

67. Z. Radak, Z. Zhao, E. Koltai, H. Ohno and M. Atalay, Oxygen consumption and usage during physical exercise: the balance between oxidative stress and ROS-dependent adaptive signaling, Antiox Redox Sig, 2013, 18, 1208-1246.

68. S. van der Sterren and E. Villamor, Contractile effects of 15-E2t-isoprostane and 15-F2tisoprostane on chicken embryo ductus arteriosus, Comp Biochem Physiol. Part A, Mol Integ Physiol, 2011, 159, 436-444.

69. G. L. Milne, Q. Dai and L. J. Roberts Ii, The isoprostanes-25 years later, Biochim Biophy Acta (BBA) - Mol Cell Biol Lipid, 2015, 1851, 433-445.

70. J.-L. Cracowski, L. Camus, T. Durand, P. Devillier, A. Guy, G. Hardy, F. Stanke-Labesque, J.-C. Rossi and G. Bessard, Response of Rat Thoracic Aorta to F2-Isoprostane Metabolites, J CardioPharma, 2002, 39, 396-403.

71. S. Medina, R. Dominguez-Perles, C. Garcia-Viguera, R. Cejuela-Anta, J. M. MartinezSanz, F. Ferreres and A. Gil-Izquierdo, Physical activity increases the bioavailability of flavanones after dietary aronia-citrus juice intake in triathletes, Food Chem, 2012, 135, 2133-2137.

72. R. Llorach, S. Medina, C. Garcia-Viguera, P. Zafrilla, J. Abellan, O. Jauregui, F. A. TomasBarberan, A. Gil-Izquierdo and C. Andres-Lacueva, Discovery of human urinary 
713

714

715

716

717

718

719

720

721

722

723

724

725

726

727

728

729

730

731

732

733

734

735

736

737

738

739 biomarkers of aronia-citrus juice intake by HPLC-q-TOF-based metabolomic approach, Electrophoresis, 2014, 35, 1599-1606.

73. A. Rahal, A. Kumar, V. Singh, B. Yadav, R. Tiwari, S. Chakraborty and K. Dhama, Oxidative Stress, Prooxidants, and Antioxidants: The Interplay, BioMed Res Intern, 2014, 2014, 19.

74. T. Turner and B. Burri, Potential Nutritional Benefits of Current Citrus Consumption, Agriculture, 2013, 3, 170-187.

75. G. Levin, M. G. Duffin K1 Fau - Obukowicz, S. L. Obukowicz Mg Fau - Hummert, H. Hummert Sl Fau - Fujiwara, P. Fujiwara H Fau - Needleman, A. Needleman P Fau - Raz and A. Raz, Differential metabolism of dihomo-gamma-linolenic acid and arachidonic acid by cyclo-oxygenase-1 and cyclo-oxygenase-2: implications for cellular synthesis of prostaglandin E1 and prostaglandin E2, Biochem J, 2002, DOI: D - NLM: PMC1222686 EDAT- 2002/04/10 10:00 MHDA- 2002/09/06 10:01 CRDT- 2002/04/10 10:00 PHST2002/04/08 [accepted] PHST- 2002/03/22 [revised] PHST- 2001/12/10 [received] AID 10.1042/BJ20011798 [doi] AID - BJ20011798 [pii] PST - ppublish.

76. J. Jamil, P. Bankhele, A. Salvi, J. E. Mannix, C. Oger, A. Guy, J.-M. Galano, T. Durand, Y. F. Njie-Mbye, S. E. Ohia and C. A. Opere, Role of the Non-enzymatic Metabolite of Eicosapentaenoic Acid, 5-epi-5-F3t-Isoprostane in the Regulation of [3H]d-Aspartate Release in Isolated Bovine Retina, Neurochem Res, 2014, 39, 2360-2369. 
Table 1. Physical and metabolic parameters and training loads of the triathletes

\begin{tabular}{|c|c|c|c|c|c|c|c|c|c|c|}
\hline \multirow{2}{*}{$\begin{array}{l}\text { Physical } \\
\text { characteristics }\end{array}$} & \multicolumn{2}{|r|}{$C-B$} & \multicolumn{2}{|c|}{$C-T$} & \multicolumn{2}{|c|}{ Placebo } & \multicolumn{2}{|c|}{$A C J$} & \multicolumn{2}{|c|}{$C P-T$} \\
\hline & Female & Male & Female & Male & Female & Male & Female & Male & Female & Male \\
\hline Years & $21.08 \pm 3.0$ & $19.0 \pm 1.7$ & $21.08 \pm 3.0$ & $19.0 \pm 1.7$ & $21.08 \pm 3.0$ & $19.0 \pm 1.7$ & $21.08 \pm 3.0$ & $19.4 \pm 1.3$ & $21.08 \pm 3.0$ & $19.6 \pm 1.3$ \\
\hline Weight (kg) & $54.8 \pm 12.2$ & $69 \pm 6.2$ & $54.8 \pm 11.6$ & $69 \pm 6.4$ & $56.2 \pm 4.8$ & $70.7 \pm 6.9$ & $54.4 \pm 5.0$ & $71.2 \pm 4.6$ & $53.1 \pm 2.9$ & $72.2 \pm 6.8$ \\
\hline Height (m) & $1.6 \pm 0.1$ & $1.8 \pm 0.1$ & $1.6 \pm 0.1$ & $1.8 \pm 0.1$ & $1.6 \pm 0.1$ & $1.8 \pm 0.1$ & $1.6 \pm 0.1$ & $1.8 \pm 0.1$ & $1.6 \pm 0.1$ & $1.8 \pm 0.1$ \\
\hline$B M I^{a}\left(\mathrm{~kg} \mathrm{~m}^{-2}\right)$ & $21.2 \pm 4.1$ & $22.2 \pm 1.0$ & $21.2 \pm 4.1$ & $22.2 \pm 1.0$ & $20.7 \pm 1.3$ & $21.7 \pm 1.4$ & $21.6 \pm 2.4$ & $21.6 \pm 1.3$ & $20.5 \pm 1.6$ & $21.8 \pm 1.7$ \\
\hline Total fat (kg) & $8.7 \pm 4.1$ & $9.2 \pm 2.8$ & $8.9 \pm 4.7$ & $8.8 \pm 2.6$ & $9.2 \pm 0.9$ & $8.0 \pm 1.7$ & $7.5 \pm 1.2$ & $6.4 \pm 2.8$ & $7.3 \pm 1.4$ & $6.8 \pm 1.2$ \\
\hline Lean weight $(\mathrm{kg})$ & $20.8 \pm 3.6$ & $31.4 \pm 2.1$ & $20.6 \pm 2.7$ & $30.5 \pm 2.7$ & $20.8 \pm 2.4$ & $31.6 \pm 3.0$ & $19.4 \pm 2.8$ & $33.8 \pm 3.2$ & $20.9 \pm 2.0$ & $32.4 \pm 2.4$ \\
\hline SS (mm) & $12.7 \pm 6.7$ & $9.6 \pm 3.0$ & $13.4 \pm 8.2$ & $9.5 \pm 2.1$ & $11.7 \pm 2.5$ & $9.1 \pm 1.7$ & $10.7 \pm 1.9$ & $8.6 \pm 2.0$ & $9.9 \pm 2.8$ & $8.6 \pm 1.8$ \\
\hline TS (mm) & $16.3 \pm 2.3$ & $8.9 \pm 3.0$ & $18.4 \pm 3.8$ & $9.7 \pm 2.6$ & $19.3 \pm 5.4$ & $8.7 \pm 2.1$ & $16.1 \pm 4.6$ & $7.4 \pm 2.4$ & $17.4 \pm 4.6$ & $7.3 \pm 1.5$ \\
\hline BS (mm) & $10.3 \pm 2.8$ & $5.4 \pm 2.4$ & $9.8 \pm 3.2$ & $4.7 \pm 1.5$ & $7.2 \pm 0.4$ & $4.1 \pm 0.6$ & $5.7 \pm 1.0$ & $4.5 \pm 1.5$ & $5.7 \pm 1.3$ & $3.7 \pm 0.4$ \\
\hline ICS (mm) & $19.7 \pm 4.5$ & $12.0 \pm 2.6$ & $17.1 \pm 6.9$ & $13.1 \pm 4.1$ & $20.9 \pm 4.5$ & $12.5 \pm 4.2$ & $17.3 \pm 3.7$ & $11.2 \pm 3.4$ & $13.7 \pm 4.3$ & $9.6 \pm 2.5$ \\
\hline SES (mm) & $14.3 \pm 6.5$ & $9.0 \pm 2.6$ & $14.4 \pm 6.9$ & $8.9 \pm 2.8$ & $15.0 \pm 1.0$ & $8.7 \pm 2.5$ & $12.8 \pm 2.1$ & $7.6 \pm 1.9$ & $11.6 \pm 2.5$ & $6.7 \pm 1.4$ \\
\hline $\mathrm{AS}(\mathbf{m m})$ & $23.1 \pm 5.9$ & $16.4 \pm 8.0$ & $23.6 \pm 6.9$ & $15.5 \pm 6.8$ & $24.5 \pm 4.7$ & $14.5 \pm 5.9$ & $21.3 \pm 4.1$ & $11.8 \pm 5.2$ & $17.9 \pm 4.6$ & $10.0 \pm 3.7$ \\
\hline FTS (mm) & $27.2 \pm 5.2$ & $14.9 \pm 4.4$ & $26.4 \pm 5.0$ & $14.0 \pm 4.4$ & $25.8 \pm 3.6$ & $11.5 \pm 2.3$ & $23.8 \pm 12.5$ & $10.1 \pm 2.9$ & $26.0 \pm 5.4$ & $10.0 \pm 2.5$ \\
\hline $\operatorname{MCS}(\mathbf{m m})$ & $14.8 \pm 3.8$ & $9.0 \pm 3.0$ & $13.9 \pm 3.0$ & $9.5 \pm 3.1$ & $15.7 \pm 2.1$ & $8.2 \pm 2.1$ & $12.5 \pm 1.8$ & $7.2 \pm 2.3$ & $14.4 \pm 2.9$ & $7.3 \pm 1.8$ \\
\hline
\end{tabular}

a Body Mass Index. Abbreviation: ACJ; Aronia-citrus Juice; AS, Abdominal skinfold; BS, Biceps skinfold; CB; Control Baseline; CP-T; Control Post-Treatment; CT; Control Training; FTS, Front Thigh skinfold; ICS, Iliac Crest skinfold; Medial Calf skinfold; SES, Supra espinale skinfold; SS, Subscapular skinfold; TS, Triceps skinfold; 
Table 2. Dietary parameters: caloric intake of the triathletes during the study and nutritional composition of the Aronia-citrus Juice (ACJ)

\begin{tabular}{|c|c|c|}
\hline A) & $\begin{array}{c}\text { Male } \\
\text { triathletes }\end{array}$ & $\begin{array}{c}\text { Female } \\
\text { triathletes }\end{array}$ \\
\hline Energy intake $\left(\mathrm{kcal} \mathrm{d}^{-1}\right)$ & $2820.0 \pm 241.2$ & $2072.6 \pm 223.4$ \\
\hline Carbohydrate $\left(\mathrm{g} \mathrm{d}^{-1}\right)$ & $326.1 \pm 63.5$ & $211.3 \pm 43.9$ \\
\hline Dietary fiber $\left(\mathrm{g} \mathrm{d}^{-1}\right)$ & $27.3 \pm 7.4$ & $15.5 \pm 4.4$ \\
\hline $\operatorname{Sugar}\left(\mathrm{g} \mathrm{d}^{-1}\right)$ & $121.3 \pm 33.9$ & $80.5 \pm 18.3$ \\
\hline Proteins $\left(\mathrm{g} \mathrm{d}^{-1}\right)$ & $133.7 \pm 12.9$ & $83.5 \pm 9.0$ \\
\hline Total lipids ( $\mathrm{g} \mathrm{d}^{-1}$ ) & $113.7 \pm 13.3$ & $107.1 \pm 14.4$ \\
\hline $\operatorname{SFA}^{\mathrm{a}}\left(\mathrm{g} \mathrm{d}^{-1}\right)$ & $33.5 \pm 6.5$ & $29.6 \pm 4.4$ \\
\hline $\operatorname{MUFA}^{b}\left(\mathbf{g ~ d}^{-1}\right)$ & $56.5 \pm 5.5$ & $56.6 \pm 7.5$ \\
\hline $\operatorname{PUFA}^{\mathrm{c}}\left(\mathrm{g} \mathrm{d}^{-1}\right)$ & $16.9 \pm 2.7$ & $15.9 \pm 6.7$ \\
\hline Vitamin $C\left(\mathrm{mg} \mathrm{d}^{-1}\right)$ & $178.9 \pm 71.9$ & $135.0 \pm 60.4$ \\
\hline Vitamin $A\left(\mu g d^{-1}\right)$ & $2970.0 \pm 913.9$ & $1427.4 \pm 573.1$ \\
\hline Vitamin $E\left(\mathrm{mg} \mathrm{d}^{-1}\right)$ & $21.0 \pm 5.6$ & $13.9 \pm 3.4$ \\
\hline Vitamin $D\left(\mathrm{mg} \mathrm{d}^{-1}\right)$ & $988 . \pm 47.5$ & $751.6 \pm 163.0$ \\
\hline Iron $\left(\mathrm{mg} \mathrm{d}^{-1}\right)$ & $20.9 \pm 2.4$ & $14.9 \pm 2.6$ \\
\hline Selenium ( $\left.\mathrm{mg} \mathrm{d}^{-1}\right)$ & $149.8 \pm 21.5$ & $103.0 \pm 17.4$ \\
\hline Water ingestion $\left(\mathrm{mL} \mathrm{d}^{-1}\right)$ & $1500 *$ & $1500^{*}$ \\
\hline B) $\mathrm{ACJ}$ & $200 \mathrm{~mL}$ & $\%$ \\
\hline Energy intake (kcal) & 76.0 & 2.6 \\
\hline Proteins (g) & 0.9 & 0.6 \\
\hline Carbohydrate (g) & 18.0 & 2,6 \\
\hline Sugar (g) & 6.6 & 5.2 \\
\hline Fat (g) & 0.1 & 0.1 \\
\hline \multicolumn{3}{|l|}{ Flavanones (mg) } \\
\hline Eriocitrin & $22.9 \pm 0.16$ & \\
\hline Hesperidin & $27.08 \pm 0.28$ & \\
\hline \multicolumn{3}{|l|}{ Flavones (mg) } \\
\hline Vicenin-2 & $1.18 \pm 0.04$ & \\
\hline Diosmetin-6,8-di- $O$-glucoside & $15.5 \pm 0.38$ & \\
\hline Diosmin & $<0.5$ & \\
\hline \multicolumn{3}{|l|}{ Anthocyanins (mg) } \\
\hline Cyanidin 3-O-galactoside & $30.16 \pm 0.20$ & \\
\hline Cyanidin 3-O-glucoside & $2.62 \pm 0.04$ & \\
\hline Cyanidin 3- $O$-arabinoside & $18.36 \pm 0.40$ & \\
\hline Cyanidin 3- $O$-xyloside & $2.22 \pm 0.03$ & \\
\hline Total anthocyanins & $53.4 \pm 0.70$ & \\
\hline \multicolumn{3}{|l|}{ Hydroxycinnamic acids (mg) } \\
\hline Neochlorogenic acid & $39.44 \pm 0.34$ & \\
\hline Chlorogenic acid & $29.38 \pm 0.26$ & \\
\hline$\sum$ Quercetin derivativesa (mg) & $8.62 \pm 0.26$ & \\
\hline
\end{tabular}

A) Dietary parameters and caloric intake of the triathletes during the study. ${ }^{\text {a }}$ Saturated fatty acids, ${ }^{b}$ Monounsaturated fatty acids, ${ }^{\mathrm{c}}$ Polyunsaturated fatty acids.* This was the daily water intake required, furthermore, the athletes drank extra liquids during the nutritional intervention $(200 \mathrm{~mL} / \mathrm{day}$ of ACJ or Placebo), as well as during their sessions of training( since $400 \mathrm{~mL}$ to $600 \mathrm{~mL} /$ hour of water). B) The nutritional composition of $\mathrm{ACJ}$; \%, contribution of the juice to the diet. The values of the phenolic content are mean \pm standard deviation $(n=3)$,

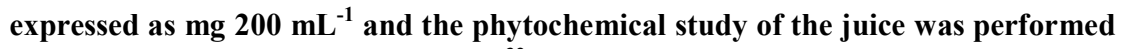
according to Gonzales-Molina, 2008. ${ }^{32}$. 
Table 3. Urinary isoprostanes and prostaglandins $\left(\mu \mathrm{g} 24 \mathrm{~h}^{-1}\right)$ from arachidonic acid, dihomo- $\gamma$-linoleic acid, and eicosapentaenoic acid detected in the urine samples of triathletes

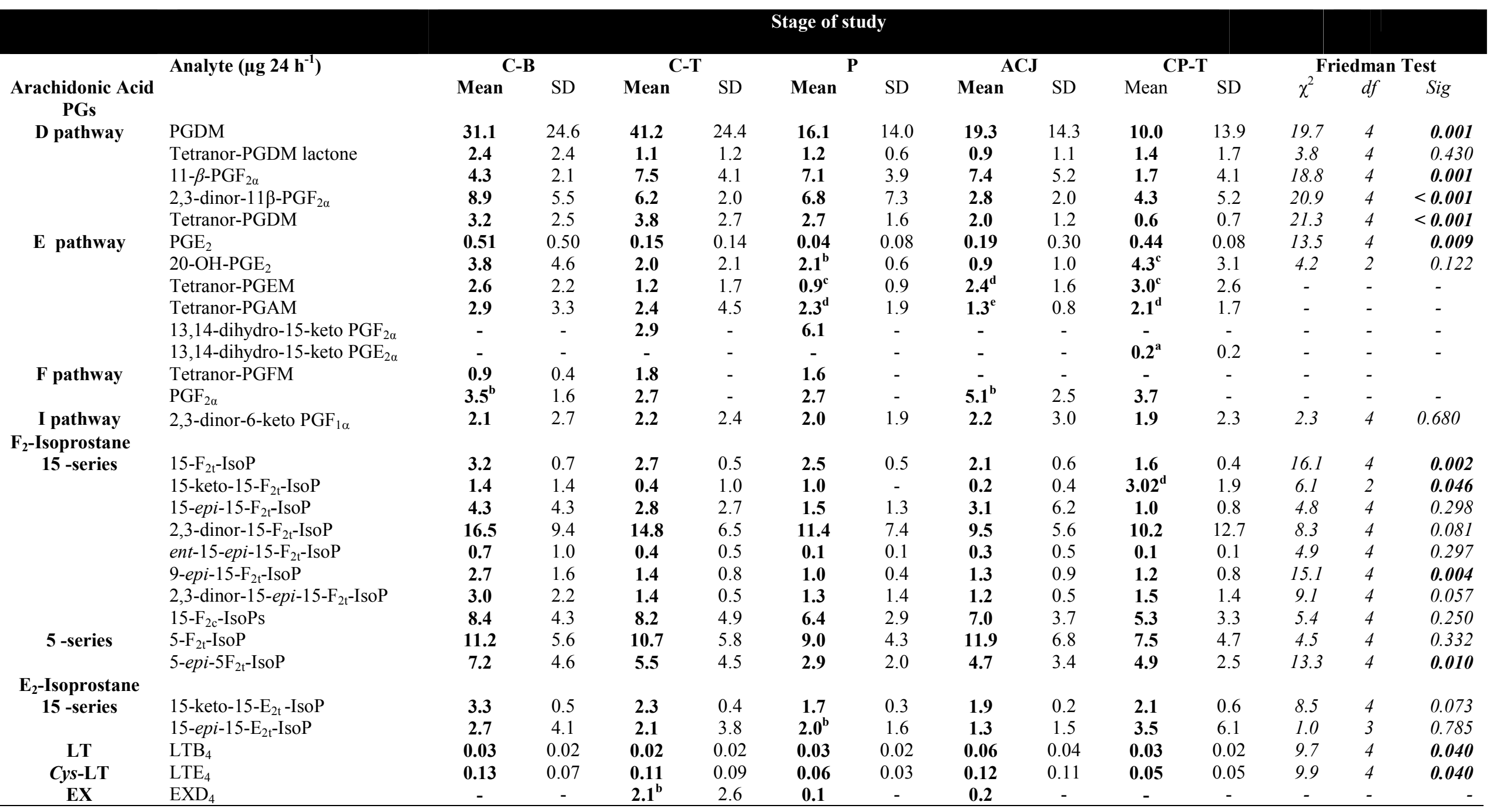




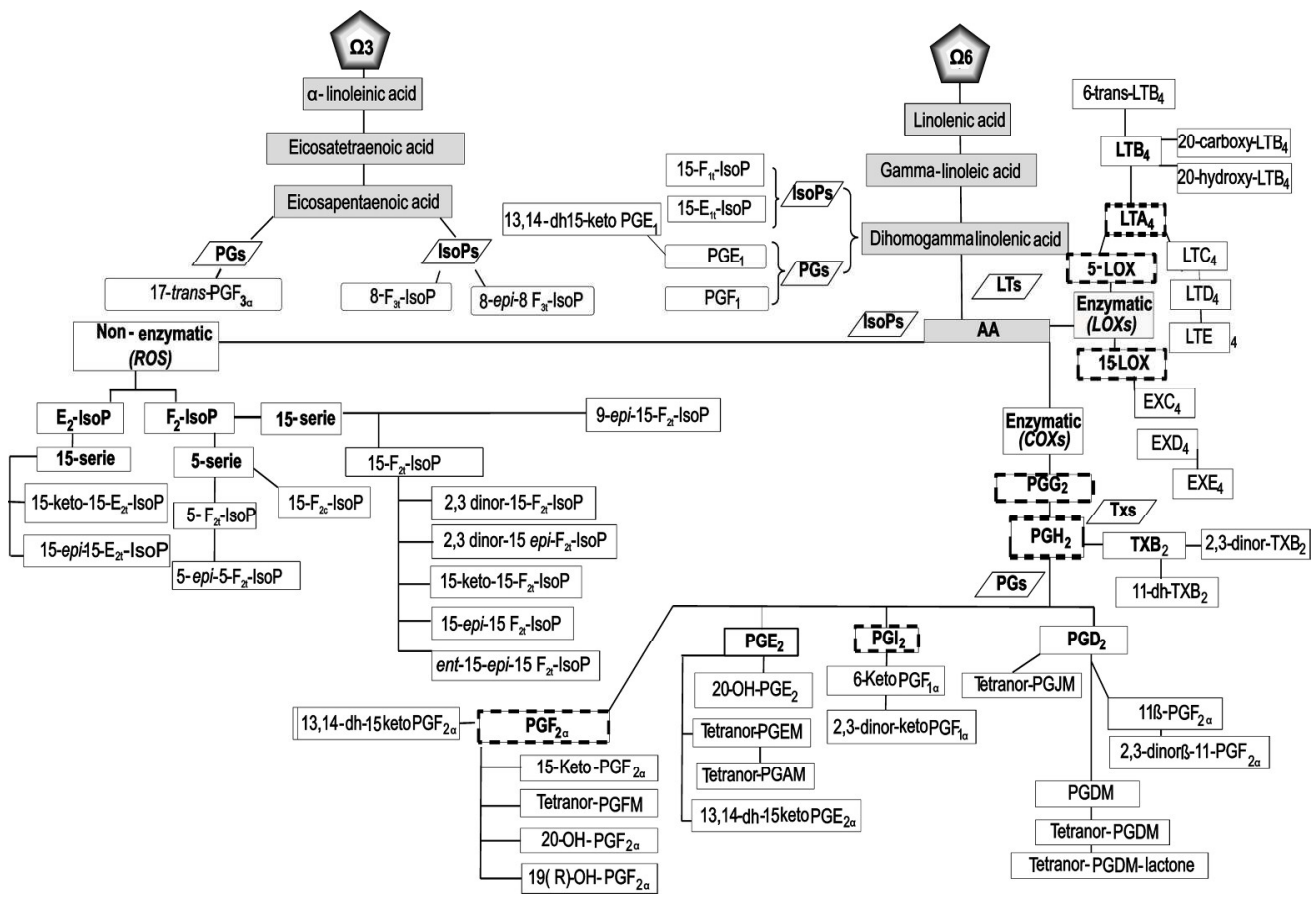

Flow chart: pathway of the oxylipins analyzed in this study. The metabolites nomenclature is described in the text.

$107 \times 72 \mathrm{~mm}(600 \times 600 \mathrm{DPI})$ 


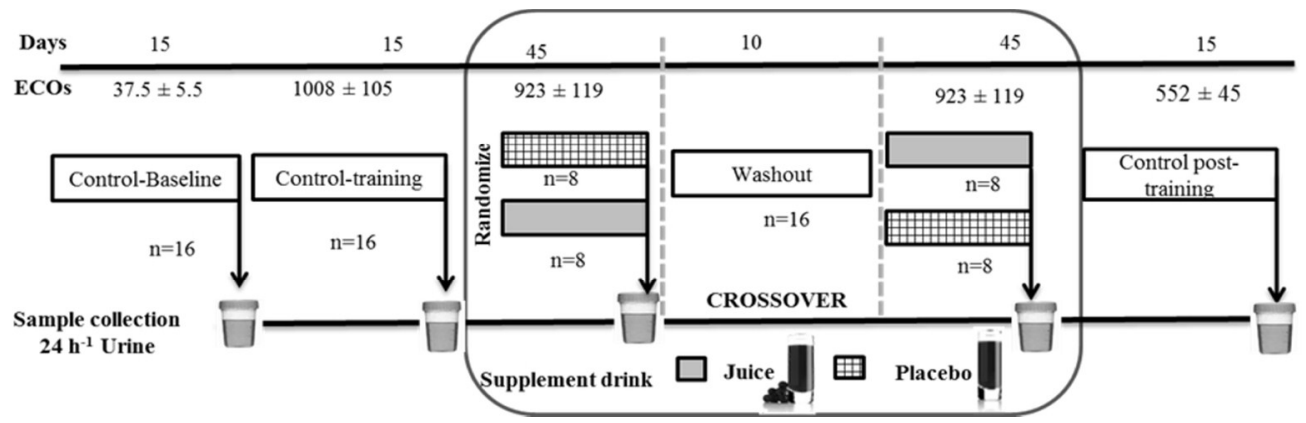

Study design: this crossover study was randomized, double-blind, and placebo-controlled. Sixteen athletes, randomly divided into two groups, were assigned to supplementation of either $200 \mathrm{~mL}$ of $\mathrm{ACJ}$ or $200 \mathrm{~mL}$ of placebo. After 45 days of supplementation and a 10-day washout period, the beverages were reversed. Three controls were used: baseline control, control training, and control post-training with duration of 15 days. Urine samples were collected at the end of each stage. The training load quantification was by the Objective Load Scale (ECOs). 5, 30, 33 
A)

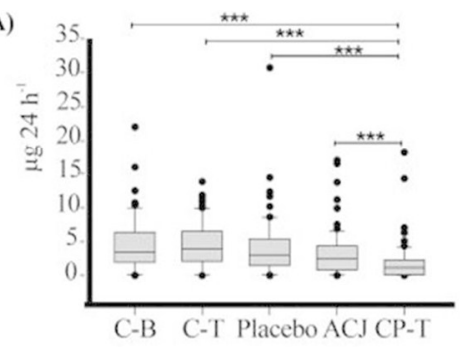

B)

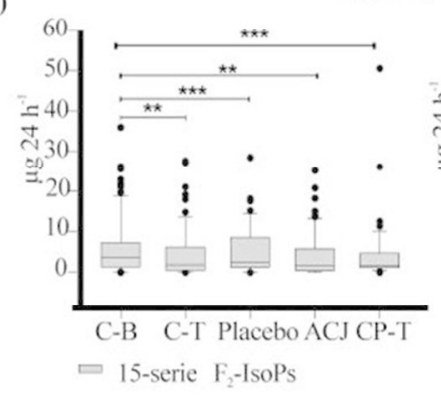

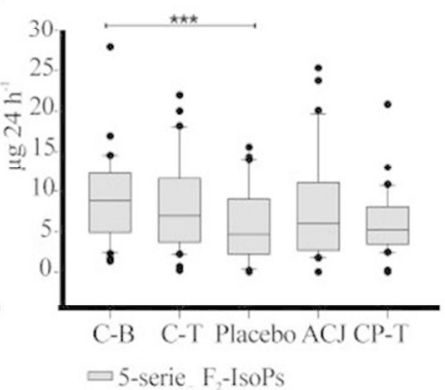

$\square 5$-serie F,-IsoPs

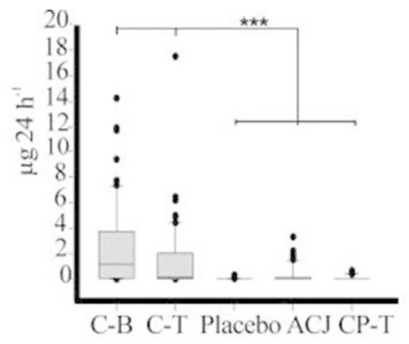

E Pathway

C)

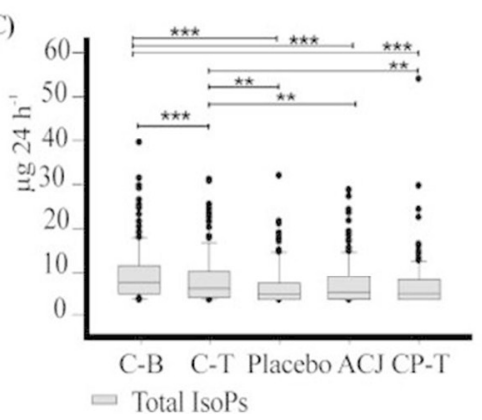

Figure 3 Box plots with quartiles (upper values 75\%, median 50\%, and lower values $25 \%$ ) of the urinary oxylipins throughout the study ( $\mu \mathrm{g} 24 \mathrm{~h}-1)$. The level of statistical significance was set at $\mathrm{P}<0.005$ with Bonferroni correction ( $* *=\mathrm{P}<0.005$ and $* * *=\mathrm{P}<0.001$ ). A) Prostaglandins by family, B) Isoprostanes by serie, and C) Total isoprostanes, both F2-isoprostanes and E2-isoprostanes.

$190 \times 181 \mathrm{~mm}(150 \times 150 \mathrm{DPI})$ 


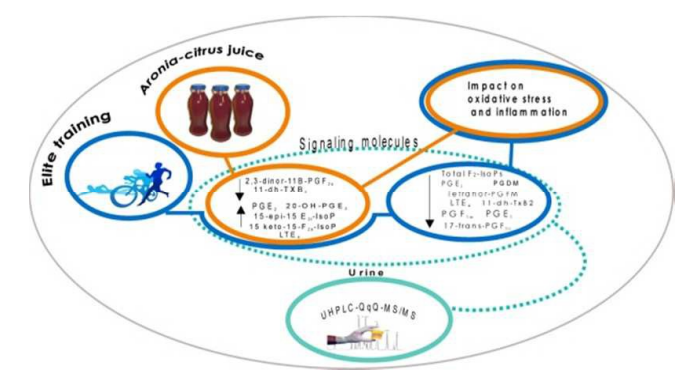

The ACJ supplementation has a potential benefit regarding the cardiovascular system that is connected in a synergistic manner with elite physical activity. 